NBER WORKING PAPER SERIES

SPECULATIVE DYNAMICS

David M. Cutler

James $M$. Zoterba

Lawrence $H$. Summers

Working Paper No. 3242

NATIONAL BUREAU OF ECONOMIC RESEARCH

1050 Massachusetts Avenue

Cambridge, MA 02138

January 1990

We are grateful to Fischer Black, John Campbell, John Cochrane, Kenneth French, Ken Froot, Lars Hansen, Bertrand Jacquillat, Andrew Lo, and Julio Rotemberg for helpful discussions, and to the National Science Foundation and Sloan

Foundation for research support. This paper is part of NBER's research program in Economic Fluctuations and Financial Markets and Monetary Economics. Any opinions expressed are those of the authors not those of the National Bureau of Economic Research. 
NBER Working Paper \#3242

January 1990

\section{SPECULATIVE DYNAMICS}

\section{ABSTRACT}

This paper presents evidence on the characteristic speculative dynamics of a wide range of asset returns. It highlights three stylized facts. First, returns tend to be positively serially correlated at high frequency. Second, returns tend to be negatively serially correlated over long horizons. Third, deviations of asset values from proxies for fundamental value have predictive power for returns. These patterns emerge repeatedly in our analyses of stocks, bonds, foreign exchange, real estate, collectibles, and precious metals, and they appear too strong to be attributed only to small sample biases. The pervasive nature of these patterns suggests that they may be due to inherent features of the speculative process, rather than to variation in risk. factors which affect particular markets.

David M. Cutler $N B E R$ and $M I T$ 50 Memorial Drive Cambridge, MA 02139
James M. Poterba

NBER and MIT

Department of Economics

Room E52-350

50 Memorial Drive

Cambridge, MA 02139
Lawrence H. Summers

NBER and Harvard

Department of Economics

Littauer 229

Cambridge, MA 02138 
The traditional efficient markets wisdom that asset returns are unforecastable has recently been challenged by a number of empirical findings Studies of the historical time series of common stock returns in the United States, for example, have uncovered serial dependence in returns and also shown that lagged dividend-price ratios can forecast a substantial fraction of return variation. Unfortunately, these results are difficult to interpret, because the underlying data set has been analyzed so many times in the search for predictable patterns in returns.

This paper provides new evidence on the robustness of these findings. We use data on stock and bond returns in 13 different countries, on the returns to holding five major currencies, as wel- as on returns to investing in gold, silver, real estate, and a variety of collectible real assets, to explore the predictability of asset returns Our results uncover several patterns which characterize the returns on most speculative assets. First, excess returns exhibit positive serial correlation at short horizons, typically over periods of one or several months. Second, returns are weakly negatively correlated over longer horizons Finaliy, crude measures of the deviation between prices and fundamental values, the analogues of the dividend-price ratio for the various assets we consider, appear to forecast future returns, particularly over long horizons Unfortunately, the limited availability of data for many of the assets we consider renders the evidence for the second and third propositions somewhat weaker than that for the positive short run serial correlation:

This paper is divided into five sections. The first section presents Monte Carlo results on the statistical power of the autocorrelation and regression tests for return predictabilizy which we use in our subsequent analysis. We find that for plausible specifications of the stochastic process 
generating returns, regression tests are likely to yield higher power than autocorrelation tests. This finding appears even when the observable proxy for the asset price fundamental is measured with substantial error. It may account for the findings of earlier research on the U.S. stock market, which have shown that dividend-price ratios have substantially greater power than lagged returns in forecasting future returns.

The next two sections apply the autocorrelation and regression tests to returns data from a variety of different asset markets. Section two analyzes the autocorrelations of excess returns, demonstrating the pronounced pattern of positive high-frequency autocorrelation and the weaker tendency for longhorizon returns to exhibit negative serial correlation. The evidence suggests this pattern in a variety of specific markets, even after accounting for the cross-correlations of returns across countries.

Section three considers the forecast power of measures of the deviation between prices and fundamental value for returns over various horizons. The findings are generally supportive of the forecast power of such measures, although the results are significantly weaker than those for the historical U.S. time series on stock returns. The point estimates for most markets, however, suggest that as much as $30-40$ percent of the deviation between prices and fundamental values is eradicated over a four year period.

Predictable patterns in asset returns could result either from changes in required returns or from inherent features of the speculative process in asset markets, which lead prices to deviate from fundamental values. ${ }^{1}$ Section four

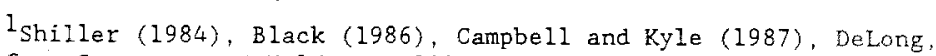
Shleifer, Summers, and Waldmann (1990), and Cutler, Poterba, and Summers (1990), among others, discuss models of asset pricing that permit prices to deviate from the rational discounted value of future cash flows. 
notes that several factors make existing theories of time-varying required returns unlikely explanations for the stylized patterns of returns which we observe First, natural characterizations of ex ante returns do not generate both positive and negative serial correlation in ex post returns. Second, our attempts to include explicit measures: of market risk premia, such as a moving average of stock return volatility, do rot reduce the forecast power of pricefundamental deviations as they should if this variable's explanatory effect results from onitted risk terms. Finally, it seems unlikely that similar. processes generate required returns in the various markets we consider, since the underlying asset fundamentals and risk factors are quite different. ${ }^{2}$

The brief concluding section suggests that explanations focusing on the nature of the speculative process itself, rather than particular risk factors, are potentially more consistent: with these stylized patterns. Although we do not present a formal model, we highlight particular features which we view as promising for inclusion in such models. These include traders who base their asset demands on prior returns, as well as traders who adapt their portfolio strategies in response to the ex post success of these different strategies. We view modelling the behavior of speculative prices in such non-tradional settings as a promising avenue for future research.

\section{Statistica1 Power of Tests for Return Forecastability}

The limited time span of asset return data makes it difficult to detect persistent deviations from martingale behavior. This proposition, stressed by

${ }^{2}$ Campbell and Hamao (1989) and Fama and French (1988a) point to similar patterns in the predictable components of equity markets, the former between the U.S. and Japan and the latter between industries; as evidence that required returns explain these findings. 
Summers (1986) with respect to Eirst order autocorrelation coefficients, has been demonstrated repeatedly even for tests based on higher order autocorrelations. $^{3}$ Not surprisingly, studies of stock returns have often failed to reject the null hypothesis of serial independence even when the point estimates suggest substantively importart mean reversion.

Studies using broader information sets than lagged returns have achieved more striking rejections of the null hypothesis that returns are unforecastable. 4 These tests use lagged values of prices relative to crude fundamentals, such as constant multiples of dividends or earnings, to forecast returns. In this section, we evaluate the power of these tests as well as traditional autocorrelation tests for detecting return forecastability.

1.1 Specification of the Null and Alternative Hypotheses

We consider a simple framework in which required returns are constant, so that in the absence of any transitory component in prices, the ratio of the price to the fundamental value would be constant. Under the null hypothesis, asset prices equal their fundamental value, and thus all movements in price are due to changes in the fundamental. The alternative is that prices contain both a transitory and a fundamental component. Since the transitory component

\footnotetext{
3 Poterba and Sumers (1988) present evidence on the low power of
} regression tests and variance ratio tests of serial dependence in returns. Both of these tests can be expressed as weighted sums of autocorrelations.

${ }^{4}$ These studies include Campbell and Shiller (1988), Fama and French (1988), and Barsky and DeLong (1989). 
decays over time, prices will display long run mean reversion. ${ }^{5}$ The test for these transitory components is then whether the excess returns implied by mean reversion are predictable given lagged information.

Formally, we write the model as:

$$
\begin{aligned}
& p_{t}=p_{t}^{*}+u_{t} \\
& p_{t}^{*}=p_{t-1}^{*}+\epsilon_{t} \\
& u_{t}=\rho u_{t-1}+v_{t} .
\end{aligned}
$$

where $p_{t}$ is the the logarithm of the real asset price ${ }^{6}, p_{t}^{*}$ is the logarithm of the fundamental component, which evolves as a random walk, and $u_{t}$ is the transitory component, which follows a first-order autoregressive process. Under the null, $u_{t}=0$ and returns are white noise. Under the alternative, as Poterba and Summers (1988) show, recurns $\left(r_{t}-p_{t}-p_{t-1}\right)$ will follow an $\operatorname{ARMA}(1,1)$ process and will therefore be partly forecastable on the basis of past information:

We assume that the econometrician can observe $z_{t}$, a noisy proxy for the asset fundamental:

$$
z_{t}=p_{t}^{*}+w_{t}
$$

where $w_{t}$ is serially uncorrelated. The proxy's information content depends on the share of the variation in $\left(z_{t}-p_{t}\right)$ that is due to the transitory component. We parameterize this as $\lambda-\sigma_{\mathrm{u}}^{2} /\left[\sigma_{\mathrm{u}}^{2}+\sigma_{\mathrm{W}}^{2}\right]$... If $\lambda-1$, then $z_{\mathrm{t}}$ equals $\mathrm{p}_{\mathrm{t}}^{*}$ Lower values of $\lambda$ imply less precise information on the fundamental.

${ }^{5}$ The alternative could equally well include changes in required returns, with observationally equivalent predictions for the time series properties of ex-post returns (Poterba and Sumners, 1988). We consider these two explanations for our findings in Section 4.

${ }^{6}$ The asset can be thought of as a futures contract with a fundamental value equal to termination value but no dividends. 
We first consider the power of autocorrelation tests to detect the forecastability of returns. The probability limit of the first order autocorrelation is:

$$
\operatorname{plim}\left(\hat{\rho}_{1}\right)=-(1-\rho)^{2} \sigma_{u}^{2} /\left(\sigma_{\epsilon}^{2}+2(1-\rho) \sigma_{u}^{2}\right)
$$

The analogous expression for higher order autocorrelations $(j>1)$ is plim $\left(\hat{\rho}_{j}\right)$

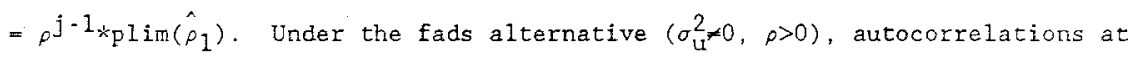
all horizons will be negative, reflecting the reversion of prices to fundamental value. The autocorrelations become smaller in absolute value as the persistence of the transitory component ( $P$ ) increases. Under the null hypothesis $\left(\sigma_{u}^{2}=0\right)$, returns are uncorrelated.

We consider autocorrelation tests based on the first order autocorrelation coefficient alone, as well as the average of atutocorrelations 1-12, 1324, and 25-36. The averages allow for the possibility that while any single autocorrelation may be difficult to distinguish from zero, persistent deviations at all lags should yield more powerful tests.

A second strategy is to predict returns using information about the relation between price and the proxy for fundamental value. To do this, we run regressions of the form:

$$
\mathrm{p}_{\mathrm{t}+\mathrm{k}}-\mathrm{p}_{\mathrm{t}}=\alpha_{\mathrm{k}}+\beta_{\mathrm{k}} *\left(\mathrm{z}_{\mathrm{t}}-\mathrm{p}_{\mathrm{t}}\right)+v_{\mathrm{t}+1, \mathrm{k}}
$$

where $p_{t+k}-p_{t}$ is the $k$-period return beginning in period $t+1$. The regression specification corresponds to previous studies of return forecastability. For common stocks, for example, if $z_{t}$ were the logarithm of the real dividend, then $z_{t}-p_{t}$ would equal the $\log$ dividend-price ratio and this regression is similar to that in Campbell and Shiller (1989) or Fama and French (1988b). The coefficients are subscripted by $k$ to reflect the possibility of estimating this equation for a variety of different return horizons. 
The probability limit of $\hat{\beta}_{k}$ is:

$$
\operatorname{plim}\left(\hat{\beta}_{k}\right)=\left(1-\rho^{k}\right) \lambda \text {. }
$$

which is positive provided $\sigma_{u}^{2}>0$ (so $\lambda>0$ ). As with the autocorrelation coefficients, mean-reverting behavior will be difficult to distinguish from random walk behavior when $\rho$ is near unity (the transitory component is highly serially correlated) or when $\lambda$ is near zero (little of the variacion in the deviation between fundamental and price is due to the transitory component).

The regression specified in (6) could be estimated using non-overlapping $k$-period observations, but that would not use all of the information in the data series. Fully efficient estimation involves estimating (6) using overlapping data. Since $v_{t+1, k}$ is correlated across observations in this case, ordinary least squares standard errors will be inconsistent We therefore apply the technique developed by Newey and West (1987) to compute consistent standard errors; we allow for $k-1$ autocorrelations of the error term. 7

\subsection{Correcting for Small Sample Bias}

Estimates of $\beta_{k}$, whether based on overlapping or non-overlapping data, are biased in small samples. In a finite data set, above-average returns in one period will tend to be associated with above-average future prices, but below-average future returns, since the average return is fixed in the sample. This implies a negative correlation between current prices and future returns,

${ }^{7}$ Hodrick and Hansen (1989) compare the statistical properties of regression tests using multi-period returns as the dependent variable (as in (6) with tests. in which single-period returns are regressed on the sum of lagged values of the independent variables $\left(z_{t}-p_{t}\right)$. Although they find the latter to be superior, we focus on equations like (6) for comparability with earlier studies. 
even if the series is a randon walk. Even when prices are calibrated relative to fundamental values, if fundamental-price ratios that are below average were preceeded by above-average past returns, they will signal below-average future returns. 8 Regression evidence will thus indicate that fundamental-price deviations predict future returns, even though the subsequent returns may be independent of the fundamental-price ratio. ${ }^{9}$

To calibrate the small sample bias we must specify the process for $z_{t}-p_{t}$ (which we denote $\mu_{t}$ ) and the effect of $\mu_{t}$ on $r_{t+j}$. In most cases $\mu_{t}$ is adequately described as a first-order autoregression:

$$
\mu_{t+1}=\phi * \mu_{t}+\eta_{t+1}
$$

In the model above, for example, $\phi=\rho * \lambda$. Because positive shocks to returns raise prices and therefore lower $z_{t}-p_{t}$, the errors in (6) and (8) will be negatively correlated: $\sigma_{v \eta}<0$. We also assume that the current value of the fundamental-price ratio sumarizes all the information in the history of $p_{t}$ and $z_{t}$ which can be used to predict returns, so that:

$$
r_{t+1}=\beta_{1} \mu_{t}+v_{t+1}
$$

Given the correlation between the errors in ( 8 ) and ( 9 ), the error in the returns equation may be written:

$$
v_{t+1}=\rho_{v \eta^{*} \eta_{t+1}}+5_{t+1}
$$

${ }^{8}$ In our specification of the null hypothesis, the fundamental-price ratio is independent of past returns, and thus there is no small sample bias. For alternative specifications of the null hypothesis, including some considered below, these error terms will be correlated, and there will be small sample bias.

${ }^{9}$ Even if all of the readjustment of the fundamental-price ratio to its average occurs through changes in the fundamental, which are not a component of returns, knowledge that the fundamental-price ratio is high imparts information about past returns, and thus about whether future returns will be above or below the sample average. 
Equation (9) does not imply that returns further in the future cannot be forecast using the current value of the fundamental-price ratio. Rather, it suggests that any such predictive power must operate through the correlation between current fundamental-price ratios and future ratios, and the predictive power of future fundamental-price ratios for future returns for example, the $j$-period ahead return can be related to $\mu_{t}$ by:

$$
\mathbf{r}_{t+j}=\gamma_{j}{ }^{*} \mu_{t}+\tilde{v}_{t+j}
$$

where $\gamma_{j}=\beta_{1} * \phi^{j-1}$. Since $\beta_{k}$ in equation (6) equals $\sum_{j=1}^{k} \gamma_{j}$, the bias in estimating $\beta_{\mathrm{k}}$ is found by computing the bias for $\gamma_{j}$ and suming the results.

The bias calculation for $\gamma_{j}$ proceeds as follows:

$$
\begin{aligned}
& \hat{\gamma_{j}}=\sum_{t=1}^{T} \mu_{t}{ }^{* r_{t+j}} / \sum_{t=1}^{T}\left(\mu_{t}\right)^{2} \\
& =\beta_{1} *\left[\sum_{t=1}^{T} \mu_{t}{ }^{*} \mu_{t+j-1} / \sum_{t=1}^{T}\left(\mu_{t}\right)^{2}\right]+\sum_{t=1}^{T} \mu_{t}{ }^{*} v_{t+j} / \sum_{t=1}^{T}\left(\mu_{t}\right)^{2} \\
& =\beta_{1} *\left(\hat{\phi}_{j-1}\right)+\sum_{t=1}^{T} \mu_{t}^{*}\left(\rho_{v \eta^{*}} \eta_{t+j}+\zeta_{t+j}\right) !_{t=1}^{T}\left(\mu_{t}\right)^{2} \\
& =\beta_{1} *\left(\hat{\phi}_{j-1}\right)+\rho_{v \eta^{*}}\left[\hat{\phi}_{j}-\phi^{*}\left(\hat{\phi}_{j-1}\right)\right] .
\end{aligned}
$$

where $\hat{\phi}_{j}-1$ is the regression estimate of the $(j-1)$ st autocorrelation of $\mu_{t}$ : Recalling that $\gamma_{j}-\beta_{1}{ }^{\psi_{\phi}}{ }^{j-1}$, we can express the bias of $\hat{\gamma}_{j}$ as:

$$
\begin{aligned}
& \operatorname{Bias}\left(\hat{\gamma}_{j}\right)=\beta_{1}^{*}\left(\hat{\phi}_{j-1}-\phi^{j-1}\right)+\rho_{u \eta}^{*}\left[\left(\hat{\phi}_{j}-\phi^{j}\right)-\phi\left(\hat{\phi}_{j-1}-\phi^{j-1}\right)\right] \\
& -\left(\beta_{1}-\rho_{\nu \eta}{ }^{* \phi}\right) *\left[\hat{\phi}_{j-1}-\phi^{j-1}\right]+\rho_{u \eta^{*}}{ }^{*}\left[\hat{\phi}_{j}-\phi^{j}\right] \text {. }
\end{aligned}
$$

Adding across $j$ to form the sum, we find the bias of $\beta_{k}$ :

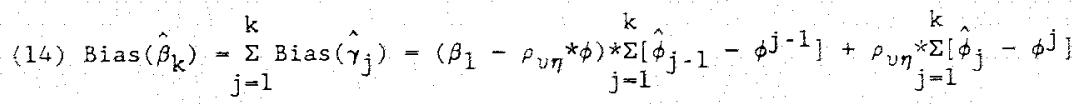




$$
=\left(\beta_{1}+\rho_{v \eta^{*}} *(1-\phi)\right) * \sum_{j=1}^{k-1}\left[\hat{\phi}_{j}-\phi j\right]+\rho_{u \eta} *\left[\hat{\phi}_{k}-\phi^{k}\right] .
$$

We simplify this expression using a result from Kendall (1973) on the small sample bias in the $j$ th estimated autocorrelation for an AR(1) process: 10

$$
E\left(\hat{\phi}_{j}\right)=\phi^{j}-\left[(1+\phi) /(1-\phi) *\left(1-\phi^{j}\right)+2 j \phi^{j} j /(T-j)\right. \text {. }
$$

The sum in equation (14) is ther: ${ }^{11}$

$$
\begin{aligned}
& \left.\sum_{j=1}^{k-1}\left[\hat{\phi}_{j}-\phi^{j}\right]=-\frac{1}{T-k}[\underset{1-\phi}{1+\phi}) *\left(k-1-\frac{\phi-\phi^{k}}{1-\phi}\right)+2 \sum_{j=1}^{k-1} j \phi^{j}\right] \\
& =-\frac{1}{\mathrm{~T}-\mathrm{k}}\left[\frac{1+\phi}{1-\phi}\left[\left(\mathrm{k}-1-\frac{\phi-\phi^{\mathrm{k}}}{1-\phi}\right)+\frac{2}{1-\phi} * \frac{\phi-\phi^{\mathrm{k}}}{1-\phi}-(\mathrm{k}-1) * \phi^{\mathrm{k}}\right)\right]
\end{aligned}
$$

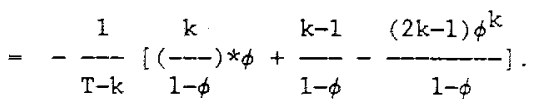

Using this expression and (15) to simplify (14) yields

$$
\begin{aligned}
\operatorname{Bias}\left(\hat{\beta}_{\mathrm{k}}\right)= & -\left[\beta_{1}+\rho_{\nu \eta} *(1-\phi)\right] *\left[\frac{\mathrm{k}-1+\mathrm{k} \star \phi-(2 \mathrm{k}-1) \phi^{\mathrm{k}}}{(1-\phi) *(\mathrm{~T}-\mathrm{k})}\right] \\
& \left.-\rho_{\nu \eta} *\left[\begin{array}{c}
1+\phi \\
1-\phi
\end{array}\right) \star\left(1-\phi^{\mathrm{k}}\right)+2 \mathrm{k} * \phi^{\mathrm{k}}\right] /(\mathrm{T}-\mathrm{k}) .
\end{aligned}
$$

${ }^{10}$ Equation (15) also shows that our autocorrelation coefficients will be biased. Under the null hypothesis of serial independence, the bias of the $j-$ th order autocorrelation is just $-1 /(\mathrm{T}-\mathrm{j})$. We therefore add $1 /(\mathrm{T}-\mathrm{j})$ to each of our estimated autocorrelations.

11 Since the bias in any autocorrelation is a function of ( $T-j$ ), the number of degrees of freedom for that autocorrelation, biases for different autocorrelations cannot generally be added. To form equation (16), we assume that each autocorrelation has the same number of observations-the fewest number for the set (T-k). Since we use only (T-k) observations in our subsequent empirical work, each autocorrelation will have only this number of observations. 
Equation (17) gives the small sample bias as a function of the autocorrelation coefficient for $\left(z_{t}-p_{t}\right)$, the correlation between the errors in the return and the fundamental-price equations, and the "truen effect of the fundamentalprice deviation on one-period ahead returns. To calculate this bias we estimate $\hat{\beta}_{I}, \hat{\phi}$, and $\hat{\rho}_{y \eta}$ for each market, and then use the estimated values in (17) to evaluate the bias. 12

We tested this bias formula using Monte Carlo simulations of one period, 12-period, and 48-period regression coefficients and biases. 13 We chose $\phi=98$, to match our empirical work, and considered 348 and 180 period samples. The results suggest two sources of inaccuracy. First, short horizon regressions are more biased than the theory suggests, while adding together returns lowers the bias. With 348 observations, the one period regression coefficient is 18 targer than the theoretical value. The 12 -period coefficient is only 118 larger than its theoretical value, however, and the 48-period coefficient is 98 below its theoretical value. With 180 observations, the average coefficients for the one and 12-period regressions are 26 and 8 larger than the theoretical value, and the 48 -period coefficient is $29 \%$ below its theoretical value.

Second, our procedure for computing the bias underestimates the theoretical value, especially at longer horizons With 348 observations, our estimates of the bias are $18,10 \%$, and $22 \%$ below the theoretical bias. With 180

12 We estimate $\hat{\rho}_{\nu \eta}$ under the null that $\beta_{1}=0$, so that $v_{t+1}=x_{t+1}$.

13 We generated 20,000 random normal vectors for $\nu$ and $\eta$ and formed returns and fundamental-price ratios assuming $\beta_{1}=0$ and $\rho_{y \eta}<0$. Since $\rho_{u \eta}$ is just a scale parameter when $\beta_{1}=0$, the results are unaffected by this value. 
observations, the underestimates are $2 \%, 17 \%$, and $37 \%$. In the 48 -period regression, this second effect dominates the first, and thus our average adjusted coefficients are positive at all horizons. In our empirical work below, we simulate p-values for $\hat{\beta}_{\mathrm{k}}$ to account for these imperfect estimates. Equation (17) suggests that the small sample bias may be quite large, particularly if the fundamental-price ratio is highly autocorrelated. An example is illustrative. For the long horizon (1926-1988) us equity data, the ordinary least squares estimates of $\hat{\beta}_{48}$ and $\hat{\beta}_{1}$ are 81.45 and 1.43 . The first order autocorrelation of the logarithm of the dividend-price ratio is 98 . The regression in equation (10) yields $\hat{p}_{v \eta}=-97.96$. These parameters imply a bias of 14.87, almost one-fifth of the estimated coefficient. Further, since the data series we consider below have at most 348 monthly observations, compared to 756 for the long horizon US data, the biases may be even more severe.

These findings of small sample bias are important because they have been neglected in many previous studies of return forecastability, such as Campbell and Shiller (1989), Fama and French (1988b), and Hodrick and Hansen (1989). Our results suggest that these findings are far weaker than ordinary inference suggests.

\subsection{Monte Carlo Results}

For each Monte Carlo experiment, we draw random normal vectors with 348 observations for $\epsilon, \eta$, and $\zeta$. These vectors correspond to twenty-nine years of monthly data. ${ }^{14}$ We form returns and fundamental-price ratios from these

${ }^{14} \mathrm{We}$ focus on this relatively short sample period because it corresponds to the data series we use below. 
vectors. In each experiment, we define the alternative hypothesis by choosing the autocorrelation of the transitory component $(p)$, the share of the variation in one-period returns which is due to the transitory factor, $\delta$ $2(1-\rho) \sigma_{u}^{2} /\left(\sigma_{\epsilon}^{2}+2(1-\rho) \sigma_{u}^{2}\right)$, and the share of the variance of the fundamental-price ratio due to the fad $(\lambda)$ : We scale these variances by fixing the variance of the fundamental innovation: $\sigma_{e}^{2} 1.15$ We define a corresponding nul1 hypothesis which equates the variance of returns, and the variance of the fundamentalprice deviation, to their values under the alternative. In each case we use the empirical distribution of the t-statistic under the null to find the critical region for a one-sided .05 test.

Table 1 reports Monte Carlo results on the power of autocorrelation tests (Panel A) and regression tests (Panel B) for predicting returns The table considers four possible stochastic processes for returns, reflecting different values of $\rho$ and $\delta$. For the regression tests, we also present results for proxies with different degrees of information content: Since the autocorrelation tests are independent of the fundamental-price ratio, they are unaffected by $\lambda$

Even with relatively noisy proxies, regression tests have significant power to detect predictability in returns... The results for po 98 (implying a half-life of the transitory component of 2.9 years) and $\delta=.75$ (three-quarters of the return variation due to the pricing fad) are the most striking In this case, regressions using one month returns have a 17.3 chance of reject-

15 By fixing the variance of the fundamental innovation, we unavoidably change the variance of the fundamental-price ratio as we vary $\lambda$ : This preserves comparability of our results with those in Poterba and Summers. (1988). An alternative strategy would be to fix the variance of returns and the variance of the fundamental-price deviation, and to allow to vary as we change the Monte Carlo specification: 
ing the null hypothesis when one-quarter of the variation in the fundamentalprice proxy is due to the fad, and a 30.58 chance when the share is one-half. Longer hortzon regressions allow an even greater chance of rejecting the null hypothesis. The power of a 48 month regression test is 65.48 when the fad accounts for one-quarter of the variance of the fundamental-price ratio, and 75.5\% when it accounts for one-half. By comparison, the most powerful autocorrelation test in this case has a power of only 9.68 .

Figure 1 shows the distribution of the t-statistic for $\beta_{48}$ under the null and alternative, using the case $\rho=.98, \delta=.25$, and $\lambda=1$. Each distribution is calculated from 25,000 Monte Carlo replications. The distribution under the null is nearly normal, with slightly thicker tails than the asymptotic distribution. ${ }^{16}$ The mean under the alternative, 2.94, is positive and large. The extent of this shift shows the substantial power of the regression test. The distribution under the alternative is also leptokurtotic, however. The 2.58 critical values are -1.2 and 8.8 . It is thus inappropriate to consult conventional t-tables for evaluating the results of long horizon regression tests. 17

16 Hodrick and Hansen (1989) report simulations of this regression specification with a greater discrepancy between true and nominal size than the simulations reported here. Unlike our specification, the null hypothesis in their model will have snall sample bias. It is unclear whether the discrepancy is due to this or to other differences in estimation.

17 Stock and Richardson (1989) raise a similar point regarding the interpretation of variance ratio statistics. 


\section{Autocorrelations of Asset Returns}

This section presents empirical evidence on the autocorrelation properties of asset returns. Our analysis considers returns from a number of stock, bond, commodity, and foreign exchange markets around the world, as well as from the markets for a variety of real assets. Analyzing many markets increases the statistical power of our tests. In addition, while risk considerations are likely to differ substantially across markets, the various maxkets will share any patterns that are common to the process of speculation.

\subsection{Asset Returns Data}

Stocks and Bonds: Our stock return data for the period 1960-1988 are drawn from Morgan Stanley's Capital International Perspectives (MSCI) 18 For each of the thirteen equity markets in our sample - Australia, Austria, Belgium, Canada, France, Germany, Italy, Japan, Netherlands, Sweden, Switzer1and, United Kingdom, and United States -- we calculate monthly excess returns $\mathrm{R}_{\mathrm{j}, \mathrm{t}}$ as

$$
R_{j, t}=\log \left(P_{j, t}+D_{j, t}\right)-\log \left(P_{j, t-1}\right)-\log \left(1+i_{j, t}\right)
$$

${ }^{18}$ The MSCI data span the period 1969-1988. For the 1960-1969 period, we use data provided by Ibbotson Associates. 
where $P_{j}$, t denotes the end-of-month price index for country $j, D_{j, t}$ dividend payments $^{19}$, and $i_{j, t}$ the monthly short-term nominal interest rate. We compute multi-period returns by summing the relevant $R_{j, t}$ values. 20

The MSCI price index for each country is a weighted average of the prices for a number of large firms in the country's equity markets. These indices generally do not correspond to other published indices, and often include shares traded on several different exchanges. Our data on government bond returns are from Ibbotson Associates World Asset Module. Short-term yields are generally Treasury bill yields, or when those are unavailable, money market yields. 21 The data sample period for each country, for both bond and stock returns, is shown in Table Al. For comparability to earliex studies, we also report the results of autocorrelation tests applied to long term U.S. historical data, drawn from Ibbotson Associates (1988), on equity and bond returns.

Foreign Exchange: We compute the excess return to holding foreign currency assuming that investors making such investments hold foreign shortterm bonds rather than just currency. This implies that the excess return to

${ }^{19}$ MSCI computes dividend yields as aggregate dividends paid over the last twelve months divided by price at the end of the reference month. For several countries, dividend yields in the early part of the sample appear to reflect actual dividend payments rather than the sum of the previous year's payments. We adjusted these yields to make them comparable with the later sample. Using "retrospective" yields will lead to errors in the measured returns, but these errors are likely to be smaller than those from omitting dividends.

${ }^{20}$ poterba and Summers (1988) analyzed real (not excess) returns excluding dividends and computed from monthly averages of stock prices as reported by the International Monetary Fund.

$2 l_{\text {The discount }}$ rate is used as the short-term interest rate for Italy, Sweden, and Switzerland. 
a. U.S. investor holding currency $j$ is:

$$
R_{\text {US }, j, t}^{\varkappa}-\log \left(E_{U S, j, t} / E_{U S, j, t-1}\right)+\log \left(1+i_{j, t}\right)-\log \left(1+i_{U S, t}\right)
$$

where the first term is the nominal appreciation of country $j$ 's currency relative to the dollar during month $t$. We focus on the returns to investors in each of five countries - France, Germany, Japan, the United Kingdom, and the United States - from holding the currency of the other four countries, yielding 10 bilateral currency returns. Our sample period for exchange rates begins in 1974, since exchange rates were fixed in earlier years. Monthly exchange rate data are from the International Monetary Fund, International Financial statistics.

Commodities: We define the return to holding gold and silver as the change in the logarithm of end-of-month closing prices. This implies an excess recurn of:

$$
R_{\text {gold }, t}=\log \left(\mathrm{P}_{\text {gold, }} / \mathrm{P}_{\text {gold }, t-1}\right)-\log \left(1+1_{\mathrm{US}, t}\right)
$$

We use data from 1974-1988, the period when gold is actively traded in a speculative market. We also study the return to holding other metals, defined as the monthly logarithmic difference in the industrial metals price index compiled by the Commodity Research Bureau for the 1959-1988 period. The components of the index are copper, lead and steel scrap, tin, and zinc.

Real Assets: We analyze returns on a variety of fixed assets: houses, farms, and various collectibles. In most cases, we measure excess holding recurns under the assumption that these assets provide no service flow:

$$
R_{j, t}=\log \left(P_{j, t} / P_{j, t-1}\right)-\log \left(1+i_{U S, t}\right)
$$

This assumption is not strictly correct, and the magnitude of the resulting measurement error is likely to vary across markets. 
We use various data sources for real asset information. House prices, available quarterly from 1970-86, and from Case and Shiller (1989). These data are constant-quality house price indices measured for four different cities. ${ }^{22}$ The data on collectibles, annual from 1967-1988, cover oriental carpets, stamps, Chinese ceramics, rare books, coins, diamonds, and old master paintings. The data are from Salomon Brothers. The farm price data are annual from 1912-86. For farms, we were able to compute a return including a crude measure of rental income, which we define as aggregate farm income divided by aggregate farm value. The capital gain is the change in average farm value per acre. Thus, our return equation in this case takes the form:

$$
R_{\text {farm, }}=\log \left(P_{\text {farm }, t}+Y_{\text {farm }, t}\right)-\log \left(P_{\text {farm }, t-1}\right)-\log \left(1+i_{U S, t}\right)
$$

where $Y_{\text {farm, }}$ is imputed per acre farm income. Data on average value per acre were obtained from the Department of Agriculture (1981 and updates)... Income data are from colling and Irwin (1989).

\subsection{Sumary Statistics}

Table 2 presents summary statistics on the means and standard deviations of annual returns for the various assets we examine. The first panel focuses on equity returns and shows substantial disparity in the mean returns across nations. In Italy, for example, the excess return on equities averaged negative thirty basis points per year during our sample, while in four countries, the annual excess return exceeds six percent. Similar, but less

${ }^{22}$ In order to avoid autocorrelation induced by measurement error, Case and Shiller formed an $A$ and $B$ price index for each city, using separate houses in each index. Our autocorrelations correlate contemporaneous values of the A series with lags of the B series. The results are very similar when the two series are reversed. 
dramatic, divergence appears for bond returns.

Table 2 also shows the correlation between U.S. dollar returns on different classes of assets. The correlation between equity and bond returns is 403 The foreign exchange portfolio - a weighted average, using 1975 GNP weights, of the returns on the pound, franc, yen, and mark - exhibits a correlation of .004 with U.S. equity returns, and its correlation with U.S. bond returns is 323 . The real assets we analyze are highly correlated with each other, but negatively correlated with many other asset returns: Gold, houses and collectibles all exhibit cross-correlations of over 45 , but the correlation between them and either stocks or bonds is small and negative: .059 and -.164 for gold. These findings suggest that our analys is of many different assets provides evidence on the behavior of speculative prices beyond that contained in equity returns.

\subsection{The Characteristic Autocorrelogram of Speculative Returns}

Tables 3 through 5 present the return autocorrelograns for the various assets. For each asset, we report the average autocorrelation over eight distinct twelve month intervals, beginning with the $1-12$ month interval, then 13-24 months, etc. We also report the first order autocorrelation coefficient itself. 23

23 We choose to study the autocorrelogram rather than the variance ratio statistic as in Kim, Nelson, and Startz (1989); Lo and Mackinlay (1989), Poterba and Summers (1988), and Stock and Richardson (1989). The variance ratio is just a weighted sum of the autocorrelations. It is not a weighted average, however, since the sum of the weights increases with the horizon being considered. Since changes in variance ratios at different horizons therefore do not shed light on changes in autocorrelations over the same horizons, we prefer to work with the autocorrelations. themselves: 
Table 3 presents the results for stocks and bonds, Table 4 the findings for foreign exchange and precious metals, and Table 5 the findings for real assets. In cases such as stocks and bonds, where we analyze data from several countries, we also report the average autocorrelation (and its standard error) at each frequency. We compute the variance of the average using the procedure developed in Poterba and Summers (1988) for estimating the cross-sectional dependence of estimated statistics, thezeby recognizing that the estimated statistics are not independent across markets. 24

In evaluating the findings in Tables 3,4 , and 5 , it is useful to recall that very small deviations of returns from the martingale assumption can imply large deviations of asset prices from fundamental values. Summers (1986) and Poterba and Summers (1988) consider an example in which the transitory component of stock prices has a standard deviation of 30 percent, a half life of three years, and accounts for three quarters of the variance in stock returns. Nonetheless it induces only an expected autocorrelation of -.007 in monthiy returns.

The first pervasive characteristic of returns in Tables $3-5$ is positive serial correlation over horizons shorter than one year. For most of the assets we consider, the first order monthly autocorrelation is positive, and the average is usually statistically significant. The values range from .020 for gold, .067 for exchange rates, .101 for common stocks, .238 for bonds, and

${ }^{24}$ If the estimated autocorrelations at a given 1 ag exhibited a constant pairwise correlation $\pi$ across countries, and if the autocorrelations for each country had constant variance $\sigma^{2}$, then the expected value of the sample cross-sectional variance of these autocorrelations would be $\sigma^{2}(1-\pi)$. Replacing the expected sample variance with its actual value, we estimate $\pi$ as $1-s^{2} / \sigma^{2}$. The variance of the sample mean for $N$ observations on different countries, each with variance $\sigma^{2}$ but with cross correlation $\pi$, is then $\sigma^{2}(1+(\mathrm{N}-1) \pi) / \mathrm{N}$. 
.269 for industrial metals. For silver, the exception to the rule, the serial correlation coefficient is -.102 .

While some have argued that non-trading effects may be relevant in assessing findings of positive autocorrelation in monthly equity returns, this explanation is implausible in the case of foreign exchange, gold or bonds. Even in the case of equities, our focus on monthly data makes non-trading unlikely as an explanation. 25

The estimated monthly autocorrelations are not only statistically but also substantively significant. They very frequently imply negative expected returns. Consider the following example. Suppose that in a given market, the monthly risk premium is $\mu$. The ex-ante risk premium on an asset will be negative if $\rho_{1} * R_{t}<-\mu$. For stocks, if one takes the risk premium to be 7 percent per month and the standard deviation of returns to be 5 percent per month, negacive expected returns would be observed more than $10 \%$ of the time 26 For bonds, where the standard deviation is only slightly smaller but the risk premium is much smaller, the calculation is even more dramatic.

Substantial autocorrelation at short horizons is particularly difficult to reconcile with traditional asset pricing models. At the monthly frequency, the probability of a negative expected return is $\Phi\left(-\mu / \rho_{1} \sigma\right)$, where $\Phi$ is the distribution function for returns. As we expand the return interval, the risk premium increases linearly while the standard deviation of returns rises with

${ }^{25}$ Lo and Mackinlay (1989a) find little support for non-trading as the explanation of positive autocorrelation in $\mathrm{U} . \mathrm{S}$ equity returns.

${ }^{26}$ This calculation assumes that returns are normally distributed. The probability of a negative expected return is $\Phi\left(-\mu / \rho_{1} \sigma\right)$, where $\Phi$ is the standard normal distribution function and $\sigma$ is the standard deviation of monthly returns. Assuming a distribution with thicker tails would strengthen our conclusion. 
the square root of the interval length. For k-period returns, therefore, the chance of a negative expected return is $\Phi\left(-k^{5} \mu / \rho_{k} \sigma\right)$, where $\rho_{k}$ is the autocorrelation coefficient for this horizon. The probability of a negative expected return is therefore higher if a given autocorrelation coefficient is observed at high Erequencies.

Fositive autocorrelation is not confined to one month returns. By subtracting $1 / 12$ of the first month's autocorrelation from the average autocorrelations over the 1-12 month interval, one finds that average autocorrelations between two and twelve months are positive for all of the asset categories. For equities, the average autocorrelation at one month is. 101 and the average over the next eleven months is .013 . For bonds, the corresponding values are .238 and .047 , while for foreign exchange the average autocorrelation at 2-i2 months is .029 . For both stocks and bonds, markets in the United States are less positively autocorrelated than are the other markets. 27 These findings strengthen earlier results, based largely on U.S. equity returns, of positive serial correlation at high frequencies. 28

For collectibles, farms, and real estate, data limitations prevent us from calculating the monthly return autocorrelation. Nevertheless, these assets show positive serial correlation in returns at an annual frequency. For house prices, the annual autocorrelation averages .206 for the four cities

27 While we focus on bonds of long duration, Gibbons (1989) reports positive serial correlation in returns on short duration, nine- and twelve-month U.S. bonds.

${ }^{28}$ poterba and summers (1988) find these patterns using monthly real and excess equity returns for the period since 1926. Lo and Mackinlay (1988) reach similar conclusions using daily data (and hence focusing on shorter time intervals) for the post-1962 period. 
in which data are available, while for farm returns ( .727$)$ and collectibles $(.365)$, the annual autocorrelations are even larger.

Tables 3 through 5 also suggest the presence of negative autocorrelation at longer lags, though the evidence on this point is less compelling than that for positive high-frequency autocorrelation. For both stocks and bonds, the average of the 13 th-24th autocorrelations is statistically significantly negative. 29 The correlation is also negative in U.S. historical data on equity returns. For bonds, the negative serial correlation persists, with negative average autocorrelations at twelve month windows up to 60 months. For exchange rates, the average autocorrelation in the second year is approximately equal to its standard error. 30 . There is also more pronounced evidence of negative autocorrelation at longer lags, notably between three and four years. There is little evidence of negative autocorrelation in the returns to holding metals, houses, or farmland, although Case and Shiller (1990) present evidence that annual real returns in the housing market are negatively autocorrelated at longer horizons. For collectibles, weak evidence of negative serial correlation emerges at the three year horizon.

The pattern of positive followed by negative return autocorrelation explains why Fama and French (1988a) find that regressing multiperiod stock returns on lagged returns yields stronger rejections of the null hypothesis of

${ }^{29}$ The negative autocorrelations for stocks during the post-1960 period are noteworthy, since $\mathrm{Kim}$, Nelson and Startz (1989) and others have emphasized the sensitivity (noted in Poterba and Sumers (1988)) of evidence for mean reversion in U.S. stock prices to inclusion of the Depression period.

${ }^{30}$ The autocorrelograms estimated here using excess foreign exchange returns look similar to those found by Huizinga (1986) for real returns. This suggests that patterns in exchange rate movements do not work through the effects of changing interest rates. 
serial independence than do variance ratio tests. The difference between these tests is that the variance ratio places declining positive weight on al1 autocorrelations up to a given lag length, while the return regressions place increasing positive weight on low-order autocorrelations and declining positive weight on higher order autocorrelations. Autocorrelation patterns such as those in Table 3 , which change sign at different lags, are more difficult to detect with a test like the variance ratio which permits positive and negative autocorrelations to cancel each other.

\section{Predicting Returns Using Information on Fundamentals}

The results in the last section suggest that asset returns are partly predictable on the basis of lagged returns information. In this section, we examine the extent to which returns over various horizons can be forecast using information on the deviation of price from estimates of fundamental value. We study returns over both short horizons - one month - as well as longer horizons - 12 and 48 months - by estimating regression equations of the form:

$$
r_{t, k}=\alpha_{k}+\beta_{k} *\left(z_{t}-p_{t}\right)+v_{t, k}
$$

As in (6) above, $r_{t, k}$ is the $k$-period asset return and $\left(z_{t}-p_{t}\right)$ is the difFerence between the logarithm of a potentially noisy measure of fundamental value and the logarithm of the asset price.

We interpret $\beta_{k}$ as the Eraction of the deviation from the price fundamental that is eradicated over a $k$ month horizon. If the current market price is one percent below the price fundamental $z_{t}$, then returns over the next $k$ months will be higher by $.01 * \beta_{k}$. Regressions estimated over various horizons 
therefore allow us to study the speed of adjustment to deviations from our price fundamental.

To test the null hypothesis that returns are unpredictable, we compute the bias-corrected t-statistic for $\beta_{\mathrm{k}}$ using the Newey-West (1987) standard error. As Figure 1 showed, the distribution of this t-statistic may be nonstandard in small samples, so it may be inappropriate to invoke large sample theory for inference. We thus simulated the t-statistic under an explicit null hypothesis, and used the resulting distribution to find empirical pvalues:

We use a similar, but more general, version of the null hypothesis from our power calculations. The model there restricted the link between fundamental-price ratios and returns to operate through the transitory component of prices. Under the null hypothesis, innovations in the fundamental-price ratio and returns were uncorrelated, and there was no small sample bias. We now relax this restriction, allowing returns to be correlated with innovations in the fundamental-price ratio, but maintaining that fundamental-price ratios have no true predictive power for returns. The null specification is thus:

$$
\begin{aligned}
& r_{t+1}=v_{t+1} \\
& \mu_{t+1}=\phi^{*} \mu_{t}+\eta_{t+1} \\
& v_{t+1}=\rho_{v \eta^{* \eta}}+s_{t+1} .
\end{aligned}
$$

By comparison, in section I we assumed that $\rho_{v \eta}=0$. We use the values of $\phi$ and $\rho_{u}$ given by the US data ${ }^{31}$, and simulate 10,000 values of the t-statistics.

${ }^{31}$ For the equity and bond markets, and the metal index, we use the values of $\rho$ and $\rho_{\text {u }}$ given by the US data from 1960-88. For the exchange rates, gold, and silver, we use the average values of $\rho$ and $\rho_{\text {un }}$ for the four currencies against the dollar. The long horizon equities and bond data use the values from the long horizon U.S. equities. 
We then calculate the p-value for each market. The p-values for the average across markets are found from the same distribution, after computing the implied standard error for the average. ${ }^{32}$

\subsection{Measuring Price Fundamentals}

For many assets, our measures of fundamentals are likely to be quite imprecise. This biases our tests against finding that the divergence between price and the measured fundamental can forecast returns, since it amounts to increasing the variance of $w_{t}$ in $z_{t}-p_{t}$. Nevertheless, under the nuIl hypothesis that asset returns are unpredictable using lagged information, none of our variables should exhibit any Eorecast power.

For equity returns, the measure of fundamental is a constant multiple of the real dividend. We then construct the logarithmic difference of this fundamental value and the price, so our regression relates ex-post returns to the logarithm of the dividend-price ratio. In the bond market, the efficient markets hypothesis and the assumption of a constant risk premium implies that the long term interest rate is a weighted average of expected future short term rates, with weights which depend on the stochastic properties of short rates. ${ }^{33}$ If short rates are a random walk, however, the long rate should equal the short rate, and the fundamental value of the long term bond is therefore the reciprocal of the short rate. Since the actual price of the long-term bond is the reciprocal of the long rate, we define $z_{t}-p_{t}$ for bonds

32 We assume that the theoretical variance of the coefficient is the average estimated variance for the different markets and use the procedure detailed in footnote 24.

${ }^{33}$ Shiller (1979) is one of many studies which presents this linearization and tests the associated model of the term structure. 
as the logarithm of the long term interest rate minus the logarithm of the short term interest rate. Regressing long-term bond returns on this variable is closely related to previous term structure equations, for example shiller, Campbe11, and Schoenholtz (1983) and Mankiw and Sumers (1984), which have regressed ex-post returns on the difference between the levels of the long and short term interest rates.

Measuring the exchange rate fundamental is more difficult than defining the fundamental for either stocks or bonds. The fundamental value of the exchange rate depends on the long run real exchange rate at which a sustainable trade balance can be achieved. Rather than attempting to model. changes in terms of trade, we simply assume that the real exchange rate consistent with long-run trade balance $\left(z_{t}\right)$ is a constant. The logarithmic difference between the fundamental and the current exchange rate is therefore just minus the logarith of the real exchange rate. We use the same approach with the metals, postulating that the fundamental is a constant, so that the price deviation is minus the logarithm of the real price 34

\subsection{Empirical Findings}

Table 6 presents evidence on the forecast power of differences between fundamentals and prices in world equity markets. The table reports regression results for three return intervals: $k$ - one month, twelve nonths, and fortyeight months The regression coefficients for each horizon are bias-adjusted

${ }^{34}$ We also experimented with allowing the fundamental value for equities, exchange rates, and metals to vary with the long term real. interest rate. The qualitative conclusions were similar to those we report below, although this modification typically raised the standard errors of our estimated coefficients, thereby lowering the statistical confidence of our findings. 
using the procedure described above. The value in parentheses beneath each coefficient is the Newey-West (1987) standard error, allowing for autocorrelation at up to k-1 lags. In light of the non-standard shape of the t-distribution as reported above, we also report (in brackets) the percentage of the distribution of t-statistics which lies above the reported value. Thus, for the Australian stock market, where the coefficient $(2.30)$ is reported in the first row of column 1 , the standard error of 1.74 implies a t-statistic of 1.32, Only 108 of the estimated t-values in our Monte Carlo analys is were greater than this value.

The results on the forecastability of monthly returns are relatively weak. The estimated coefficient on $z_{t}-P_{t}$ has a p-value less than 10 for omly three of the thirteen countries, although the cross-country average (reported in the penultimate row) has a p-value of .07 . The point estimates, however, suggest substantively important links between the dividend-price ratio and subsequent returns. The average value of $\beta_{1}, 0.75$, implies that the ex-ante risk premium is negative whenever dividend yields are less than approximately forty percent below their average value. The average $\beta_{1}$ also suggests that about three-quarters of one percent of any deviation between the current price and our dividend-based price fundamental is corrected in the first month after such a deviation appears.

The center columns in Table 4 report regressions for twelve month returns. The pattern of coefficients is similar to the one month returns. In four of the thirteen countries, the coefficient has a p-values less than .10 ; the p-value for the average, however, is .03 . The most notable outlier is Japan, where the coefficient is negative and statistically significant. For the United States, where for comparative purposes the last row in the table 
reports the long-horizon (1926-1988) results, the forecast power of the dividend-price ratio appears smaller in recent years.

On average, approximately fifteen percent of a deviation from the price fundamental is erased over the subsequent year. Since the average value of $\beta_{12}$ is about seventeen times the average for $\beta_{1}$, the evidence suggests that the dividend-price ratio's forecast power for one period returns grows slightly as the horizon grows. More importantly, however, since twelve month returns aggregate many consecutive one-period returns, each of which is partly forecastable, the twelve month return regressions yield much clearer evidence on the link between the dividend-price ratio and subsequent returns.

The final columns present evidence for 48 -month returns.. Although the sample size for these regressions is limited, the results provide strong evidence on the predictive power of dividend-price ratios. The average correction to deviations between the current price and our simple measure of fundamentals is forty-one percent over a four year horizon. This estimate has a p-value of 06 . These results suggest that dividend-price ratios exhibit substantial forecast power for long term excess returns, confirming earlier findings based on U.S. time series data.

The statistical confidence of these results are nevertheless much weaker than might have been expected in light of earlier findings for the Uniced States This is due to three factors First the corrections we nake for small sample bias significantly reduce the average regression coefficients Table 7 illustrates the detailed bias correction for the case of 48 -month return regressions. The average bias for the 13 countries is 26.67 . This correction, which has not been used in many prior studies, is of first-order importance. Second, taking account of the leptokurtotic distribution of the 
t-statistic under the null hypothesis reduces substantially the confidence associated with any given t-statistic. For the 348 month sample, the 05 cutoff in the 48-month regression t-statistic is 4.02 , much larger than the asymptotic value, which previous studies have used. Finally, it appears that the ordinary least squares regression relation between future returns and past values of the dividend-price ratio is weaker in recent years.

We now consider the forecastability of returns in the bond market. Regressions relating multi-month excess returns on long-term bonds to lagged values of the long-short yield differential are reported in Table 8 . The results are less consistent than those from the equity markets and provide weaker evidence on the forecast power of fundamental-price deviations. For one month returns, the yield spread has statistically significant explanatory power in five of the thirteen bond markets we consider, and the cross-country average is also statistically significant. The coefficient implies about the same amount of mean reversion as for the equity market: eight-tenths of one percent of a fundamental-price disparity is corrected over a one month horizon.

At the 12-month horizon, only two of the thirteen countries evidence statistically significant links between yield differentials and subsequent returns on long bonds, and the average is quite low. At longer horizons, as the column for 48-month returns shows, the standard errors on the estimated coefficients increase and it becomes difficult to draw any conclusions. Most of the long-horizon coefficients are negative, contrary to the prediction of our earlier analysis that high prices relative to fundamentals should signal lower subsequent returns. None of the findings are precise enough, however, to reject the null hypothesis that long-horizon bond returns are not forecas- 
table. In contrast, the results for the U.S. bond returns in the last row of Table 8 suggest substantial return forezast power, but with only about six percent of fundamental-price deviations corrected over 48 month horizons.

Table 9 presents the results of relating currency returns to the deviation between real exchange rates and our estimate of their fundamental value. These results also suggest little evidence for the predictability of returns. While some of the point estimates, notably for the US, Japan, and the UK, are quite large, most of the coefficients are small and have large standard errors. The average correction is only 9 percent after one year, and thirtyone percent after four years, both with very large standard errors. Although the results are weak, this is partly the result of the small samples we analyze for exchange rates. These samples make the sma11 sample bias very large (on average 59.32 ), and also require large t-statistics to reject the nul1. The os cutaff in the distribution of the null, for example, is 7.08

Table 10 presents results for commodity metals. Once again the point estimates suggest that low fundamental-prices signal low subsequent returns, but the statistical confidence of these results is low For both gold and silver, the estimated coefficients on 48 -month returns imply that deviations between prices and fundamental values are more than eradicated over this interval. Although the t-statistics in each case are well above three, the skewed nature of the distribution for this statistic renders the associated pvalues only .22 (silver) and .06 (gold)

Given the small samples for the real assets, we do not estimate equations like (6) for these assets. Case and Shiller (1990), however, report evidence that rental-to-price ratios positively predict future returns in the cities for which they have data. If the discount rate is constant, the rental-to- 
price ratio can be interpreted as a constant multiple of the fundamental-price ratio.

Our results on the predictive power of deviations between actual prices and plausible measures of price fundamentals, while weak, suggest that earlier findings that the dividend-price ratio forecasts stock returns in the U.S. are part of a more general pattern across equity markets. For all the assets except bonds, the point estimates suggest at least 30 to 40 percent mean reversion over a four year interval. For most markets other than equities, however, the brevity of our sample makes the resulting estimates imprecise.

The pattern of both positive autocorrelation and reversion to fundamentals documented in this and the previous section is consistent with Frankel and Froot's (1987) survey evidence on foreign exchange market expectations. They find that traders have extrapolative short run expectations, reflecting a belief that trends persist, but long run expectations based on fundamentals. This pattern is rational if excess returns on currencies exhibit positive short term and negative long term autocorrelation. It is also the premise of technical strategies which seek to catch trends in short-term investing, as well as long-run "value investing" strategies of the type advocated by Graham and Dodd (1934). The remainder of this paper considers two alternative explanations, one based on time-varying risk factors and the other on the dynamics of speculative trading, which might explain these empirical reguiarities. 
4. Alternative Explanations for these Patterns

One explanation of the stylized patterns in asset returns is that they are caused by changes in risk factors over time. Such an argument is difficult to rule out, since any failure of an asset pricing model can always be attributed to the mismeasurement of risk. Changing required returns appear unlikely, however, to explain our empirical findings.

First, traditional models in financial economics have difficulty justifying substantial risk premia, let alone substantial variation in these risk premia. Mehra and Prescott (1985) show that the average excess return on the U.S. stock market since 1926 is too large to be consistent with plausible estimates of risk aversion and the observed riskiness of stock returns. Erankel $(1985,1986)$ ) argues that risk premia of more a few bas is points are not supported by standard capital asset pricing models 35 Yet, as our foregoing results suggest, positive autocorrelation in returns implies large swings in ex-ante recurns.

Second, changing risk factors would not naturally produce the observed autocorrelation patterns, particularly positive autocorrelation at high frequencies. 36 one would expect increases in risk that raise future ex-ante returns to be capitalized into a current negative excess return. For simple specifications of the risk process, this would would lead to negative autocor-

${ }^{35}$ Friedman (1985) shows that under standard capital asset pricing models, the equity premium observed during this period is enough to make investors almost wholly concentrate in equity securities.

36 Marcus (1989) and Cecchetti; Lam and Mark (1989) among others argue that changes in stock prices change the wealth of investors, affecting their risk aversion and thus expected returns. Whatever the merits of this argument in the case of stocks, it is much less likely to apply in the case of inside assets like bonds, or assets like gold and metals that comprise only a small fraction of the representative investors' portfolio. 
relation at high frequencies. While it is possible to generate processes for risk factors which are consistent with the observed autocorrelation in returns, as for example in Poterba and Summers (1988, footnote 27), they do not agree with the processes suggested by empirical work on the evolution of volatility. 37

Third, since returns on the various assets analyzed in the last section are only weakly correlated, it is unlikely that a single risk-factor could account for the statistical regularities in all markets. Some assets are affected primarily by nominal factors while others are influenced primarily by real factors; some represent large shares of investors' wealth while others represent small shares; some yield variabie cash flows while others are a source of stable income; some have finite horizons while others do not. It would be remarkable if a common risk factor could account for the common patterns in returns on all assets. ${ }^{38}$ Indeed, it is not even clear how risk should affect all the assets we analyze. In the case of foreign exchange, for example, risk affects both currencies being exchanged, and so does not even have a predictable effect on the level of exchange rates. 39

${ }^{37}$ Poterba and Summers (1986) and French, Schwert, and Stambaugh (1987) find that volatility exhibits substantial positive autocorrelation, with little evidence of the complex dynamics needed to explain positive followed by negative autocorrelation in returns.

${ }^{38}$ For equities, changes in dividends may precede increases in risk premia and lead to the appearance of spurious positive autocorrelation in ex-post returns. Even if this were correct, it is difficult to see how analogous explanations could operate in the case of gold, long-term bonds, or foreign exchange.

${ }^{39}$ Theories of exchange rate determination that rely on asset substitutability, for example, imply that the effect of exchange rate risk will depend on the relative supplies of assets across countries and savings propensities in different countries, variables which are likely to change over time. 
A fowrth difficulty with the required returns explanation is the weak empirical association between variations in ex-post returns and changes in measurable aspects of risk. Campbell and Shiller (1989) find that while dividend yields have predictive power for subsequent dividend growth in long period U.S. data, they do not have predictive power for interest rates or other determinants of risk premia. Cutler, Poterba and Summers (1989) have trouble explaining more than half of the variation in U.S. stock returns on the basis of news, even after controlling for changes in volatility. Meese and Rogoff (1983) report similar findings in their study of the foreign exchange market

As further evidence on this point, Table 11 augments our estimates of the 1 ink between equity returns and fundamental-price deviations, presented in Table 6, to include a measure of market volatility. We define volatility as the logarithm of the sum of squared monthly returns over the previous year. 40 If part of the dividend yield's explanatory power arises from its proxy role for risk factors such as volatility, adding volatility to the equation should reduce the coefficients on the log dividend-price ratio. 41

40 We also used volatility measures over longer horizons without finding any differences.

${ }^{41}$ The bias calculation detailed above extends easily to multivariate regression. In the system

$$
\begin{aligned}
& r_{t+1}=x_{t} b_{1}+u_{t+1} \\
& x_{t+1}=x_{t}^{* A}+v_{t+1} \text { and } \\
& u_{t+1}=v_{t+1}^{*} p_{u v}+e_{t+1}
\end{aligned}
$$

where $x_{t}=1 \times k, b_{1}=k \times 1, A=k \times k, v_{t+1}=1 \times k$, and $P_{u v}=k \times 1$, the bias is:

$$
\operatorname{bias}\left(\hat{b}_{1}\right)=\left[\left(\mathbf{x}_{t}^{\prime} \mathbf{x}_{t}\right)^{-1}\left(\mathbf{x}_{t}^{\prime} \mathbf{x}_{t+1}\right)-\mathbf{A}\right] \mathbf{P}_{\mathbf{u v}}
$$

If; further, $A$ is assumed diagonal, this reduces to a series of univariate biases, which may be summed as before to produce the $k$-period bias.: Since. the average correlation across the 13 equity markets between the innova- 
The results provide little support for the conjecture that risk factors explain the link between fundamental-price deviations and subsequent returns. The coefficient on the logarithm of the dividend-price ratio is virtually unaffected by the inclusion of volatility. In the 48-month regression, for example, the average coefficient on the price deviation is 51.6 , compared to 41.2 for the equation without the control for volatility. Further, while volatility generally has a positive effect on subsequent returns, it is often quite small. This increase in the average coefficient is the opposite of what would be predicted if the relationship were due solely to omitted risk factors. In that case, controlling for risk should reduce $\beta_{k}$. We have also tried including real interest rates and other proxies for risk factors in the equations, with results similar to those for volatility.

\section{Conclusions}

Our empirical results suggest three stylized facts about speculative returns. First, returns tend to be positively serially correlated at high frequency. Second, returns tend to be (weakly) negatively serially correlated over long horizons. Third, deviations of asset values from proxies for fundamental value have predictive power for excess returns. These patterns appear difficult to explain on the basis of time-varying required returns. In contrast, the similarity of these patterns in a wide range of asset markets suggest the possibility that they are best explicable, as a consequence of the speculative process itself.

tion in the logarithm of dividend yields and the innovation in the logarithm of volatility is .028 , this seems appropriate. 
Research directed ar formalizing the dynamics of speculative markets is just beginning. One strand of research, for example Kyle (1985) and Black (1986), has considered the role of heterogeneous investor information in accounting for asset price movements. A second research program, typified by Shiller (1984) and DeLong; Shleifer, Sumers, and Waldmann (1990); has modelled asset market equilibrium when some investors are uninformed but engage in transactions nonetheless. Such "noise traders" may cause prices to deviate from fundamental values. Finally, a third line of research tries to formalize the role of "history-based trading." In Cutler, Poterba and Summers (1990) we outline a model of asset market equilibrium in which interactions between rational investors, who base demand on expected future returns, and backward-looking traders, can produce the stylized facts we document here. We consider two types of backward-looking investors: fundamentals traders, who look at prices relative to perceived fundamentals, following strategies advocated by, for example, Graham and Dodd (1934); and feedback traders, who base demand on past returns. Feedback trading would result, for example, from portfolio insurance or margin-call induced selling; and has been highlighted by Kindleberger (1978) in his analysis of speculative bubbles.

In this framework, positive short run serial correlation of returns can result if some fundamentals traders learn news only with a lag, or if some feedback traders "lean into the wind" to prevent price movements, as central banks do in the foreign exchange market. Positive feedback traders who respond to such positive autocorrelation and who base their demand on past returns can generate the pattern of positive and negative autocorrelation seen in the data. By prolonging the impact of fundamental news, positive feedback traders can lengthen the horizon over which returns are positively serially 
correlated. They may also cause prices to over-shoot their long run value, however, thus inducing negative serial correlation at some horizon. This overshooting also causes the deviation of price and fundamental value to predict subsequent returns.

Further research is needed to explore models of speculation. Leland (1987) argues that if positive feedback trading becomes sufficiently important, it is possible for the market to have multiple equilibria, so that discontinuous responses of prices to fundamentals are possible. The effect of learning, with traders switching to trading strategies which have been profitable, could generate important new dynamics in these models. Perhaps the greatest need, however, is to develop testable implications of these models. It may be possible to make predictions, for example, about the amount of positive feedback trading and market volatility, volume, or other observable market characteristics. Such testable predictions are vital if the i. iterature on alternatives to traditional asset pricing models is to advance beyond the realm of speculation. 


\section{References}

Barsky; Robert and $J$. Bradford Delong, "Why Have Stock Prices Fluctuated?," mimeo, Harvard University, 1989

Black, Fischer, "Noise," Journal of Finance 41 (July 1986), 529-542.

Campol1, John $Y$ : and Yasushi Hamao, "Predictable Stock Returns in the United States and Japan: A Study of Long-Term Capital Market Integration", NBER Working Paper No: 3191; December 1989.

Campbe11, John Y. and Albert S. Kyle, "Smart Money, Noise Trading, and Stock Price Behavior", mimeo, Princeton University, 1987.

Campbel1, John Y. and Robert Shiller, "Stock Prices, Earnings, and Expected Dividends;" Journal of Finance 43. (July 1988), 661-676.

Cample11; John $Y$, and Robert Shiller, "The Dividend-Price Ratio and Expectations of Future Dividends and Discount Factors" " Review of Einancial Studies 1 (1989), 195-228.

Case, Karl E., and Robert J: Shiller; "The Efficiency of the Market for Single-Family Homes, " American Economic Review, March 1989, 125-137.

Case, Karl E., and Robert J: Shiller, "Forecasting Prices and Excess Returns in the Housing Market", mineo, Yale University, 1990

Cecchetti, Stephen G., Pok-sang Lam, and Nelson C. Mark, "Mean Reversion in Equilibrium Asset Prices," NBER Working Paper 2762, Cambridge MA., November 1988

Colling, Phil L, and Scott H. Irwin,. "Has the Farm Asset Market Been Too Volatile," mimeo, Ohio State University, May 1989.

Cutler, David M., James M. Poterba and Lawrence H. Summers, "What Moves Stock Prices?". Journal of Portfolio Management 15(Spring 1989), 4-12.

Cutler, David M. , James M. Poterba, and Lawrence H. Sumers, "Speculative Dynamics and the Role of Feedback Traders", forthcoming; American Economic Review; May 1990.

DeLong, J. Bradford, Andrei Shleifer, Lawrence Sumers, and Robert Waldmann, "Noise Trader Risk in Financial Markets", Journal of Finance, forthcoming, 1990 .

Fama, Eugene and Kenneth French, "Permanent and Transitory Components in Stock Prices," Iournal of Political Economy 96; 1988a; 246-273.

Fama, Eugene and Kenneth French, "Dividend Yields and Expected Stock Returns," Journal of Financial Economics $22,1988 \mathrm{~b}, 3-27$.

Franke1, Jeffrey A., "Portfolio Crowdiag-Out Empirically Estimated", Quarterly Journal of Economics, 100 (Supplement 1985), 1041-1065. 
Frankel, Jeffrey A., "The Implications of Mean-Variance optimization for Four Questions in International Macroeconomics", Journal of InternaEional Money and Finance 5 (1986), S53-S75.

Frankel, Jeffrey A. and Kenneth A. Froot, "Using Survey Data to Test Standard Propositions Regardirg Exchange Rate Expectations, "American Economic Review 77 (1987), 133-153.

French, Kenneth, G. William Schwert, and Robert Stambaugh, "Expected Stock Returns and Stock Market Volatility, " Journal of Financial Economics 19 (September 1987), 3-30.

Friedman, Benjamin, "The Substitutability of Debt and Equity Securities", in B. Friedman, ed., Corporate Capital Structures in the United States, Chicago: University of Chicago Press, 1985.

Gibbons, Michael, "On the Volatility of Bond Prices", Carnegie-Rochester Conference Series on Public Pclicy 31 (Autumn 1989), 139-176.

Graham, Benjamin, and David Dodd, Eecurity Analysis (New York: McGraw Hill, 1934).

Hodrick, Robert J. and Lars Feter Hansen, "Dividend Yields and Expected Stock Returns: Alternative Procedures for Inference and Measurement", mimeo, University of Chicago, 1989.

Huizinga, John, "An Empirical Investigation of the Long-Run Behavior of Real Exchange Rates," Garnegie-Rochester Conference Series on Public Bolicy 27 (1987), 149-214.

Ibbotson Associates. Stocks, Bonds, Bills and Inflation. Chicago: Ibbotson Associates, 1988 .

Keim, Donald and Robert Stambaugh, "Predicting Returns in the Stock and Bond Markets," Journal of Financial Economics 17 (1986), 357-390.

Kendall, Maurice G. Time Series, New York: Harper \& Row, 1973.

Kin, Myung Jig, Charles R. Nelson, and Richard Startz, "Mean Reversion in Stock Prices? A Reappraisal of the Empirical Evidence", NBER Working Paper No. 2795, December 1988

Kindleberger, Charles P., Manias, Panics, and Crashes New York: Basic Books, 1978 .

Leland, Hayne E. "On the Stock Market Crash and Portfolio Insurance", mimeo, University of California, Berkeley, December 1987.

Lo, Andrew W. and A. Craig MacKinlay, "Stock Market Prices Do Not Follow Random Walks: Evidence from a Simple Specification Test", Review of Financial Studies, (1988), 41-66. 
Lo, Andrew. W. and A. Craig Mackinlay, "An Econometric Analysis of Nonsynchronous Trading", Sloan School of Management Working Paper No. 3003-89-EFA, MII, 1989.

Mankiw, N. Gregory and Lawrence H. Summers, "Do Long Term Interest Rates Overreact to Short-Term Interest Rates?;" Brookings Papers on Economic Activity $1: 1984 ; 223-242$.

Marcus; Alan J., "An Equilibriun Theory of Excess Volatility and Mean Reversion in Stock Market Prices", mimeo, Federal Home Loan Bank Board, Reston: VA, June 1989.

Meese; Richard A: and Kenneth Rogoff, "Empirical Exchange Rate Models of the Seventies: Do They Fit Out of Sample", Journal of International Economics, (1983), 3-24.

Mehra, Rajnish and Edward Prescott, "The Equity Premium: A Puzzle", Journal of Monetary Economics 15 (1985); 145-162.

Newey, Whitney, and Kenneth D. West, "A Simple Positive Semi-Definite Heteroscedasticity and Autocorrelation Consistent Covariance Matrix," Econometrica $55(1987), 703-706$.

Poterba, James and Lawrence Sumers; "The Persistence of Volatility and Stock Market Fluctuations"; American Economic Review, 76 (December $1986) ; 1142-1151$.

Poterba; James and Lawrence Sumers; "Mean Reversion in Stock Prices: Evidence and Implications, "Journal of Financial Economics 22 (1988), $27-60$.

Shiller, Robert, "The Volatility of Long-Term Interest Rates and Expectations Models of the Term Stcucture," Journal of Political Economy 87 (1979), 1190-1219.

Shiller, Robert, "Stock Prices and Social Dynamics " Brookings Papers on Economic Activity $1984: 2,457-498$.

Shillex, Robert, John Y. Campbe11, and Kermit Schoenholtz, "Forward Rates and Future Policy : Interpreting the Term Structure of Interest Rates;" Brookings Papers on Economic Activity $1: 1983,173-217$.

Stambaugh, Robert, "Bias in Regressions with Lagged Stochastic Regressors," CRSP Working Paper No. 156, January 1986.

Stock, James H. and Matthew Richardson, "Is There Mean Reversion in Stock Prices? Drawing Inferences from Statistics Based on Multi-Year Asset Returns", mimeo, Harvard University, 1989.

Summers, Lawrence H. "Does the Stock Market Rationally Reflect Fundamental Values?", Journal of Finance 41. (July 1986); 591-601.

United States. Department of Agriculture. Farm Real Estate Market Developments. August 1981 (and unpublished updates). 
Table 1: Power of Autocorrelation and Regression Tests

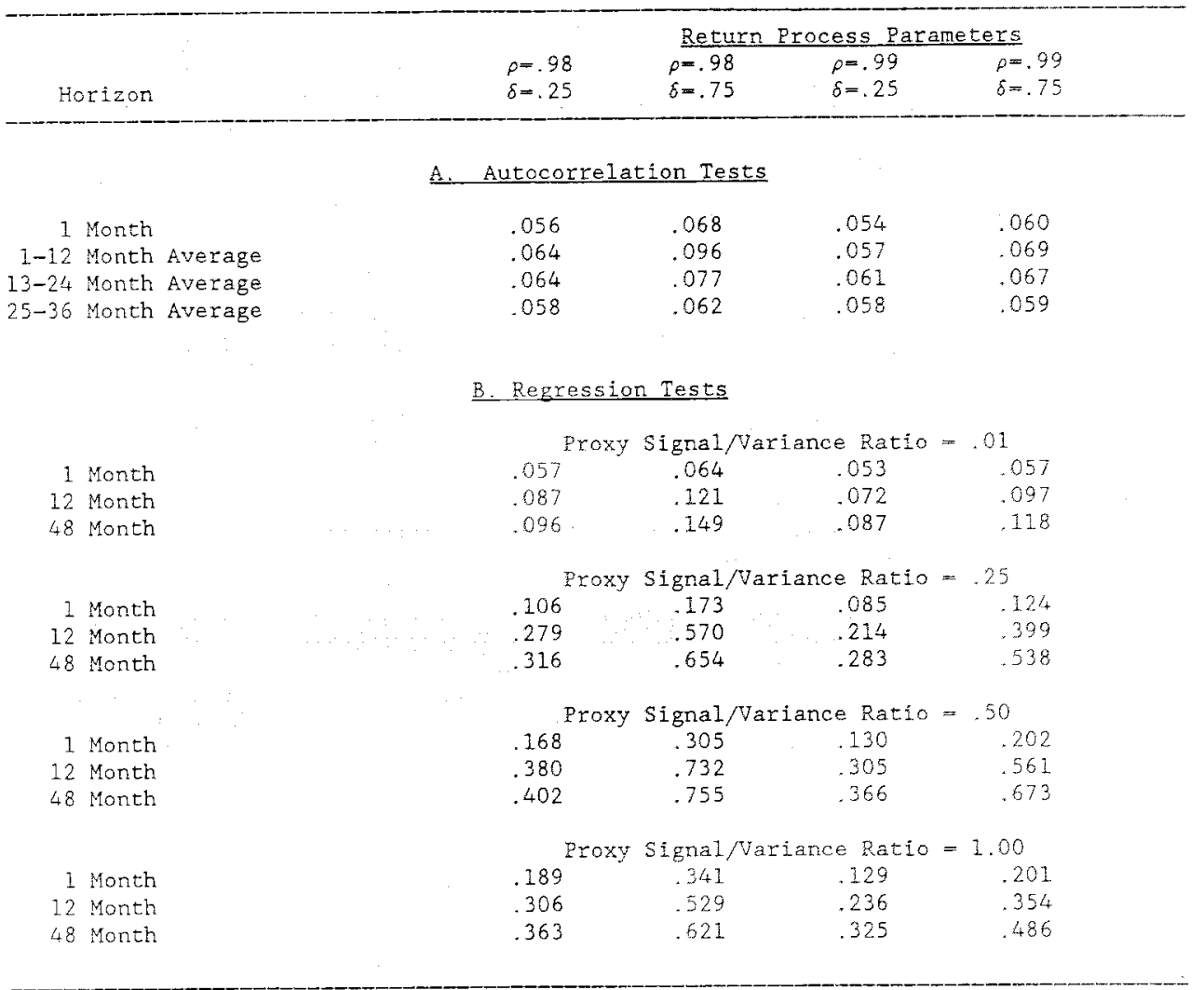

Panel A shows the empirical power of a one-tail autocorrelation test, and Panel $B$ shows the empirical power of a one-tail regression test, both with size=.05. The critical values are found from the distribution of the test statistic under the null. Each simulation draws 348 observations for the null and alternative. Panel A is based on 20,000 simulation; Panel $B$ is based on 5,000 simulations. 


\section{A. Equity and Bond Markets}

\section{Excess Return (Relative to Short Term Yield) \\ Long Term}

Equity

$(1960-1988)$

Government Bond

$(1960-1988)$

Country
Australia
Austria
Belgium
Canada
France
Germany
Italy
Japan
Netherlands
Sweden
Switzerland
United Kingdom
United States

\begin{tabular}{|c|c|}
\hline Mean & Std Devn \\
\hline 1.27 & 26.17 \\
\hline 1.60 & 12.70 \\
\hline 7.91 & 16.55 \\
\hline 2.29 & 18.55 \\
\hline 1.04 & 20.86 \\
\hline 2.76 & 17.98 \\
\hline 0.31 & 23.40 \\
\hline 7.11 & 16.83 \\
\hline 6.59 & 17.51 \\
\hline 6.38 & 18.43 \\
\hline $2.58:$ & 17.24 \\
\hline 3.87 & 22.28 \\
\hline 62 & 15.18 \\
\hline
\end{tabular}

\begin{tabular}{rr} 
Mean & Std Devn \\
\hline-2.12 & 9.78 \\
3.72 & 4.06 \\
-0.33 & 4.58 \\
-0.17 & 7.22 \\
-0.46 & 5.92 \\
2.13 & 5.09 \\
0.03 & 7.56 \\
0.96 & 5.00 \\
1.74 & 6.27 \\
-1.20 & 5.68 \\
1.80 & 4.51 \\
-0.27 & 10.55 \\
-0.45 & 10.05 \\
&
\end{tabular}

B. Alternative Assets

Mean

Std Devn

\begin{tabular}{cc} 
Currency & Gold \\
\hline 2.19 & -0.81 \\
10.16 & 25.27
\end{tabular}

\section{$\frac{\text { Silver }}{-5.20}$}

48.93
Metals
$-1.57$
14.11

\section{Houses \\ 0.37}
3.27

Collectibles

4.35

12.32

\section{Correlations for Annual U.S. Dollar Returns}

\begin{tabular}{|c|c|c|c|c|c|c|}
\hline & US Equities & US Bonds & Currency & Gold & Houses & Collectibles \\
\hline US Equities & 1.000 & 1000 & & & & \\
\hline $\begin{array}{l}\text { US Bonds } \\
\text { Currency }\end{array}$ & $\begin{array}{r}.403 \\
.004\end{array}$ & $\begin{array}{r}1.000 \\
323\end{array}$ & 1.000 & & & \\
\hline Gold & -.059 & -.164 & 425 & 1.000 & & \\
\hline Houses: & -.036 & -.144 & 566 & 566 & 1.000 & \\
\hline Collectibles & .306 & -.084 & 300 & .458 & 821 & 1.000 \\
\hline
\end{tabular}

Note: Equity and government bond returns are in own currency and are relative to the short term yield. The correlation matrix uses data for the United States only. The currency return is the weighted average dollar excess return to holding the Pound, Mark, Yen and Franc, where the weights are 1975 GNP (in dollars). Appendix Table A-1 contains the sample period for the equity and bond market returns. Currency, gold and silver returns are from 1974-1988. Industrial metals returns are from 1959-199. House returns are from 1970-1986. Farm returns are from 1912-1986. Collectibles returns are from 1968-1988, and average the returns of the available assets each year. The sample period for each correlation is the shorter of the two assets. 


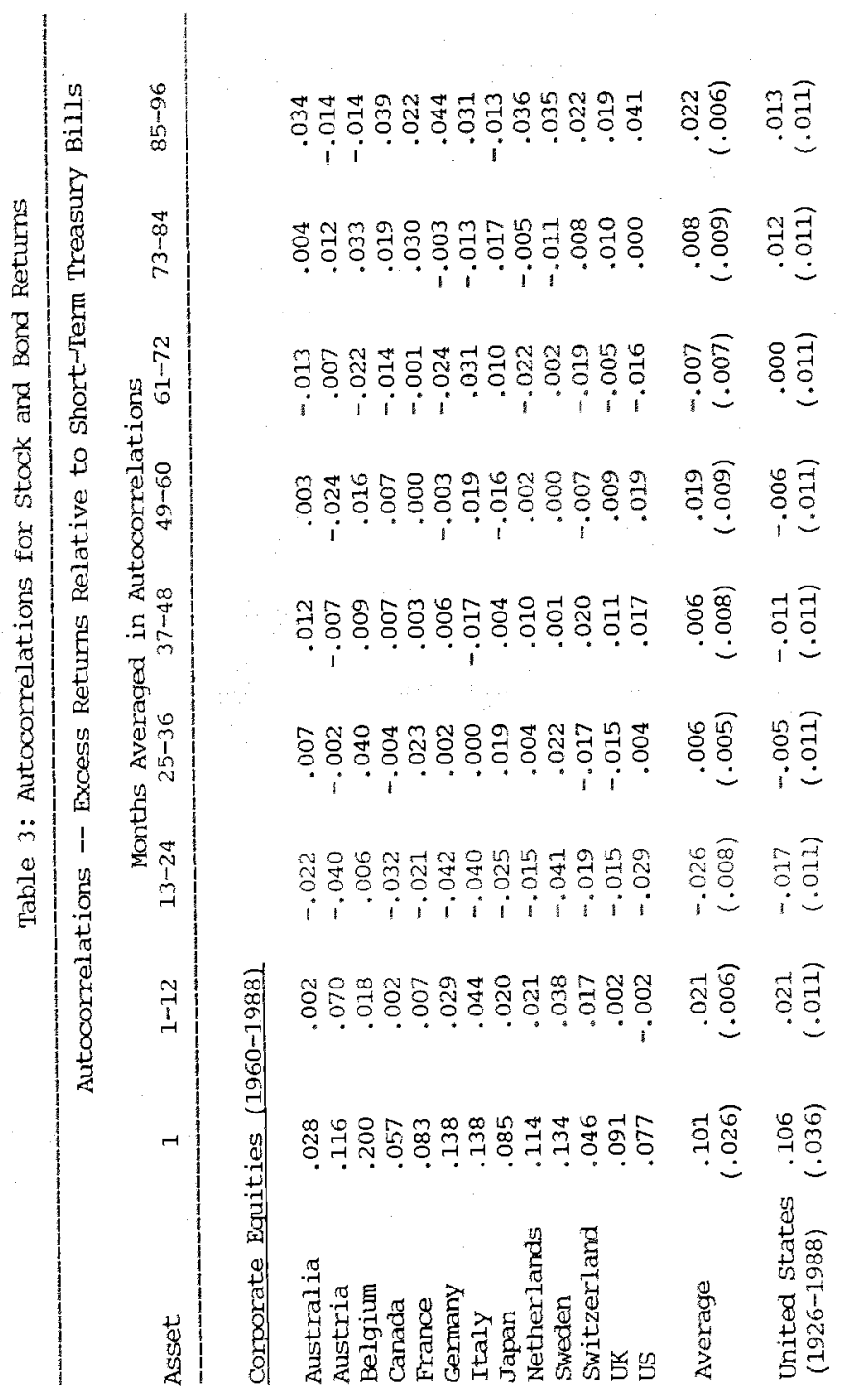




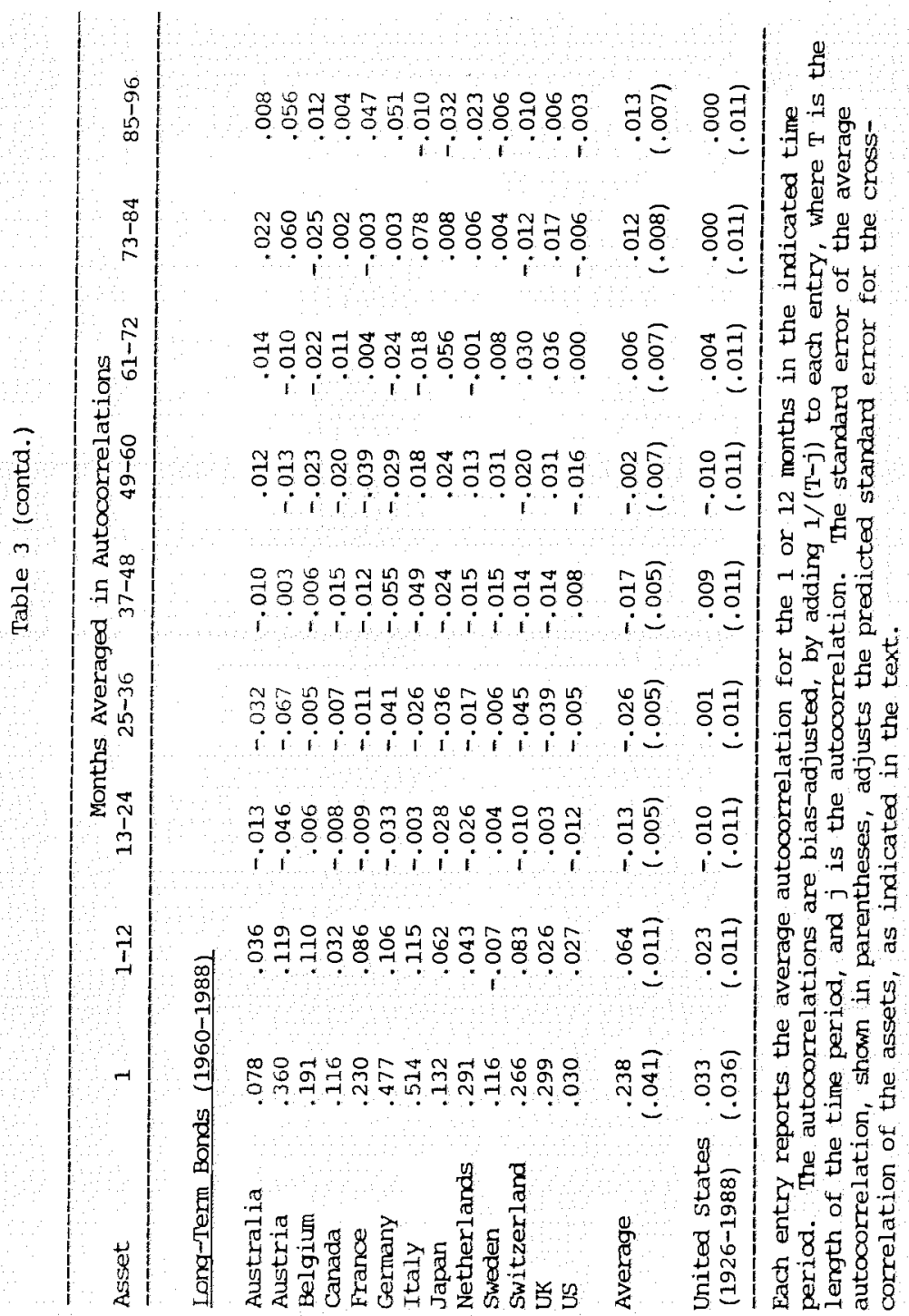




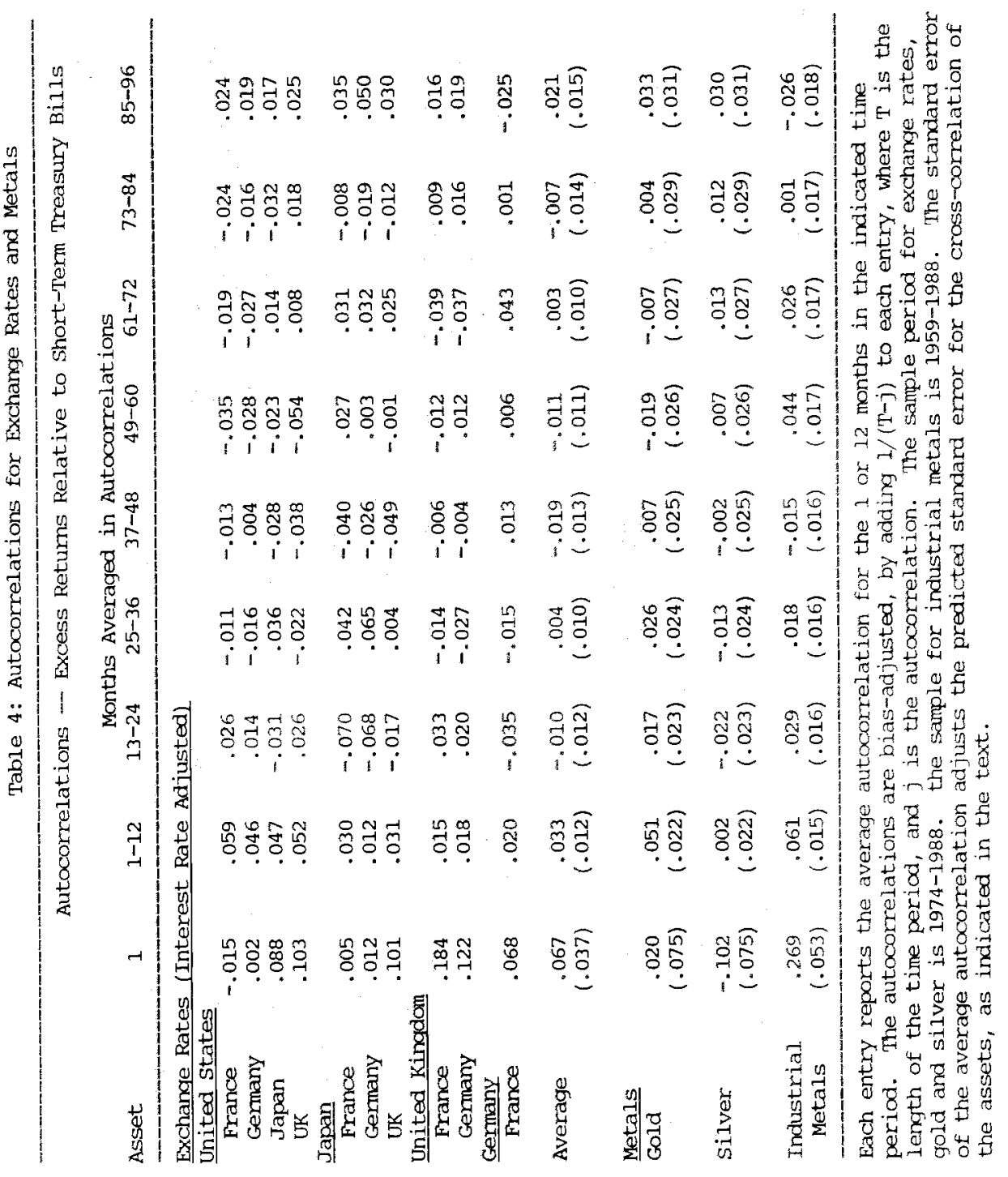


Table 5: Autocorrelations for Alternative Assets

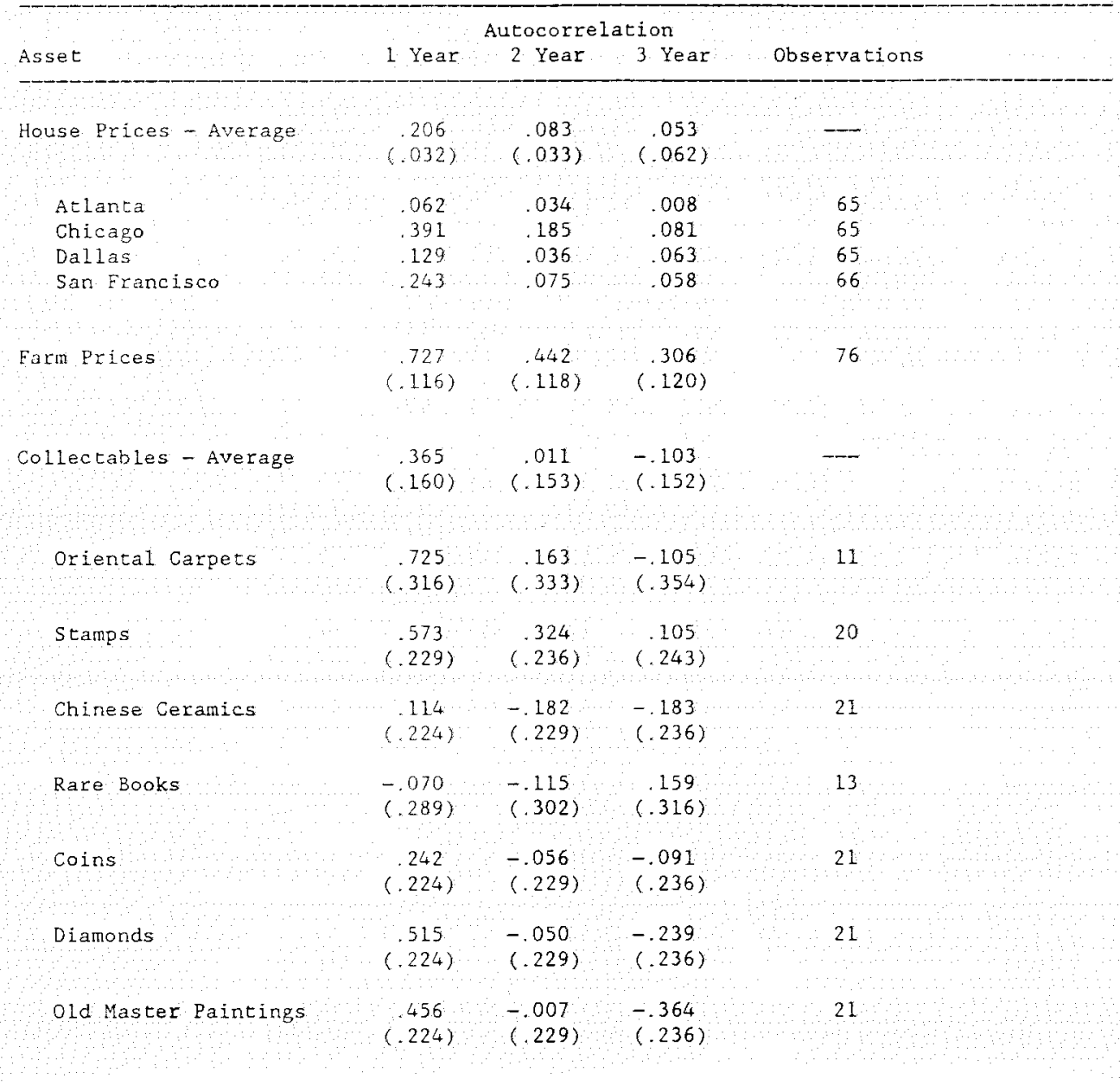

Each entry reports the autocorrelation for the year indicated. House price data are quarterly from 1970:1 to 1986:2 (1986:3 for San Francisco); see Shiller and Case. (1987) for a description. Farm price data are annul from 1912-1986; the capital gain is from Department of Agriculture (1988); dividend income is fxom Colling and Irwin (1989). Data on other assets are annual from 1967 or later and were supplied by Salomon Brothers. The standard errors for the averages take account of the cross correlation between assets. For the collectibles, the theoretical standard deviation is assumed to be that for: the asset with the fewest observations (11). 
Table 6: Forecasting Excess Stock Returns Using Dividend-Based Fundamentals

\begin{tabular}{|c|c|c|c|c|c|c|c|c|c|}
\hline Country & $\beta_{1}$ & $\begin{array}{l}1 \text { Month } \\
\text { p-value }\end{array}$ & $\bar{R}^{2}$ & $\beta_{12}$ & $\begin{array}{l}12 \text { Month } \\
\text { p-value }\end{array}$ & $\overline{\mathrm{R}}^{2}$ & $\beta_{48}$ & $\begin{array}{l}48 \text { Month } \\
\text { p-value }\end{array}$ & $\overline{\mathrm{R}}^{2}$ \\
\hline Australia & $\begin{array}{c}2.30 \\
(1.74)\end{array}$ & {$[0.10]$} & .014 & $\begin{array}{l}32.77 \\
(7.80)\end{array}$ & {$[0.01]$} & .240 & $\begin{array}{c}85.07 \\
(11.62)\end{array}$ & {$[0.01]$} & .572 \\
\hline Austria & $\begin{array}{l}-1.59 \\
(0.90)\end{array}$ & {$[0.95]$} & .004 & $\begin{array}{c}-8.74 \\
(12.79)\end{array}$ & {$[0.68]$} & -.002 & $\begin{array}{c}35.25 \\
(56.08)\end{array}$ & $\{0.41\}$ & .032 \\
\hline Belgium & $\begin{array}{l}-0.62 \\
(0.91)\end{array}$ & {$[0.71]$} & -.004 & $\begin{array}{l}-0.46 \\
(8.88)\end{array}$ & {$[0.52]$} & .015 & $\begin{array}{c}26.04 \\
(31.47)\end{array}$ & {$[0.37]$} & .202 \\
\hline Canada & $\begin{array}{c}1.30 \\
(1.81)\end{array}$ & {$[0.23]$} & .004 & $\begin{array}{c}27.07 \\
(12.28)\end{array}$ & {$[0.08\}$} & .132 & $\begin{array}{c}43.91 \\
(16.65)\end{array}$ & {$[0.14]$} & .249 \\
\hline France & $\begin{array}{c}0.48 \\
(0.86)\end{array}$ & $\{0.28\}$ & .005 & $\begin{array}{c}8.94 \\
(6.05)\end{array}$ & {$[0.17]$} & .101 & $\begin{array}{c}45.42 \\
(17.80)\end{array}$ & {$[0.13]$} & .440 \\
\hline Germany & $\begin{array}{l}-0.04 \\
(1.03)\end{array}$ & {$[0.50]$} & .000 & $\begin{array}{c}11.04 \\
(10.30)\end{array}$ & {$[0.24]$} & .091 & $\begin{array}{c}40.50 \\
(21.54)\end{array}$ & {$[0.21]$} & .395 \\
\hline Italy & $\begin{array}{c}0.59 \\
(1.21)\end{array}$ & {$[0.31]$} & -.001 & $\begin{array}{c}18.81 \\
(10.08)\end{array}$ & {$[0.12]$} & .063 & $\begin{array}{c}5.20 \\
(40.33)\end{array}$ & {$[0.51]$} & .000 \\
\hline Japan & $\begin{array}{l}-1.10 \\
(0.41)\end{array}$ & {$[0.99]$} & .002 & $\begin{array}{r}-13.19 \\
(4.56)\end{array}$ & {$[0.97]$} & $\therefore .034$ & $\begin{array}{l}-56.71 \\
(24.22)\end{array}$ & {$[0.90]$} & .098 \\
\hline Netherlands & $\begin{array}{c}0.46 \\
(1.29)\end{array}$ & {$[0.36]$} & .002 & $\begin{array}{c}11.95 \\
(12.11)\end{array}$ & $10.26 !$ & .089 & $\begin{array}{c}71.09 \\
(24.46)\end{array}$ & {$[0.10\}$} & .461 \\
\hline Sweden & $\begin{array}{l}-0.23 \\
(0.97)\end{array}$ & {$[0.57]$} & -.002 & $\begin{array}{c}12.32 \\
(10.21)\end{array}$ & {$[0.22]$} & .083 & $\begin{array}{c}51.64 \\
(40.52)\end{array}$ & {$[0.29]$} & .278 \\
\hline Switzerland & $\begin{array}{c}2.70 \\
(1.64)\end{array}$ & {$[0.06\rceil$} & .014 & $\begin{array}{c}28.20 \\
(11.18)\end{array}$ & {$[0.06]$} & .122 & $\begin{array}{l}73.58 \\
(33.52)\end{array}$ & {$[0.17]$} & .291 \\
\hline $\begin{array}{l}\text { United } \\
\text { Kingdom }\end{array}$ & $\begin{array}{c}5.11 \\
(1.62)\end{array}$ & {$[0.01]$} & .018 & $\begin{array}{c}43.90 \\
(11.62)\end{array}$ & {$[0.01]$} & .268 & $\begin{array}{c}94.39 \\
(17.98)\end{array}$ & {$[0.02]$} & .516 \\
\hline $\begin{array}{l}\text { United } \\
\text { States }\end{array}$ & $\begin{array}{c}0.54 \\
(1.00)\end{array}$ & {$[0.29]$} & .002 & $\begin{array}{l}11.43 \\
(8.99)\end{array}$ & {$[0.21]$} & .080 & $\begin{array}{c}20.06 \\
(21.17)\end{array}$ & {$[0.35]$} & 202 \\
\hline Average & $\begin{array}{c}0.75 \\
(0.50)\end{array}$ & {$[0.07]$} & & $\begin{array}{l}14.16 \\
(4.50)\end{array}$ & {$[0.03]$} & & $\begin{array}{c}41.20 \\
(10.87)\end{array}$ & {$[0.06]$} & \\
\hline $\begin{array}{l}\text { US } \\
1926-1988\end{array}$ & $\begin{array}{c}0.01 \\
(0.78)\end{array}$ & {$[0.47]$} & .003 & $\begin{array}{l}17.44 \\
(8.46)\end{array}$ & {$[0.06]$} & .077 & $\begin{array}{c}66.58 \\
(14.45)\end{array}$ & {$[0.01]$} & .296 \\
\hline
\end{tabular}

Each entry reports estimates of the coefficient $\beta_{1, k}$ from the regression:

$$
\mathrm{R}_{\mathrm{t}, \mathrm{k}}=\alpha_{\mathrm{k}}+\beta_{\mathrm{k}}{ }^{*}\left(z_{\mathrm{t}}-\mathrm{p}_{\mathrm{t}}\right)+v_{\mathrm{t}, \mathrm{k}}
$$

where $z_{t}$ is the logarithm of the real dividend. Data are from 1960-1988; see Appendix Table AI for specifics. The coefficients are bias-adjusted. Numbers in parentheses are standard errors, calculated using the Newey-West procedure. The standard error of the average accounts for cross correlation of the coefficients, as in the text. Number in brackets are p-values for the null hypothesis that the coefficient is zero, based o the Monte Carlo distribution of the adjusted t-statistic. 
Table 7: Calculation of Small Sample Bias for Equity Markets

\begin{tabular}{|c|c|c|c|c|c|}
\hline Country & $\beta_{48}$ & $\beta_{1}$ & $\begin{array}{c}\text { nents } \\
\quad \rho\end{array}$ & as & Bias \\
\hline Australia & 103.32 & 3.60 & 0.95 & -78.87 & 18.24 \\
\hline Austria & 75.85 & -0.95 & 0.98 & -54.67 & 40.59 \\
\hline Belgium & 66.73 & 0.54 & 0.98 & -73.62 & 40.69 \\
\hline Canada & 72.45 & 2.75 & 0.96 & -93.08 & 28.54 \\
\hline France & 71.94 & 1.50 & 0.98 & -81.88 & 26.52 \\
\hline Germany & 71.17 & 0.95 & 0.98 & -87.51 & 30.58 \\
\hline Italy & 20.52 & 1.27 & 0.96 & -52.56 & 15.32 \\
\hline Japari & -18.03 & -0.41 & 1.00 & $-60 \cdot 30$ & 38.68 \\
\hline Netherlands & 101.91 & 1.71 & 0.97 & -85.20 & 30.82 \\
\hline Sweden & 85.41 & 0.78 & 0.99 & -77.33 & 33.77 \\
\hline Switzerland & 85,08 & 3.62 & 0.94 & -71.79 & 11.50 \\
\hline United Kingdom & 107.44 & 4.28 & 0.96 & -90.62 & 13.05 \\
\hline United States & 38.43 & 1. 27 & 0.97 & -64.94 & 18.37 \\
\hline United States & 81.45 & 1.43 & 0.98 & -97.96 & 14.87 \\
\hline
\end{tabular}

The table show the components of the small sample bias for 48 -month dividend-price ratio regressions. $\beta_{48}$ is the unadjusted 48 -month regression coefficient. $\beta_{1}, \rho$ and $\rho_{u}$ are the estimated coefficients for that country. The final column shows the bias estimate. 
Table 8: Forecasting Long-Term Excess Holding Returns With Wield Spreads

\begin{tabular}{|c|c|c|c|c|c|c|c|c|c|}
\hline Country & $\beta_{1}$ & $\begin{array}{l}1 \text { Month } \\
\text { p-value }\end{array}$ & $\bar{R}^{2}$ & $\beta_{12}$ & $\begin{array}{l}12 \text { Month } \\
\text { p-value }\end{array}$ & $\overline{\mathrm{R}}^{2}$ & $\beta_{48}$ & $\begin{array}{l}48 \text { Month } \\
\text { p-value }\end{array}$ & $\overline{\mathrm{R}}^{2}$ \\
\hline Australia & $\begin{array}{c}0.11 \\
(1.17)\end{array}$ & {$[0.45]$} & -.004 & $\begin{array}{c}-7.66 \\
(12.21)\end{array}$ & {$[0.66]$} & .009 & $\begin{array}{l}-26.45 \\
(34.76)\end{array}$ & {$[0.69]$} & .029 \\
\hline Austria & $\begin{array}{c}1.33 \\
(0.55)\end{array}$ & {$[0.01]$} & .023 & $\begin{array}{c}3.27 \\
(9.16)\end{array}$ & {$[0.41]$} & -.002 & $\begin{array}{c}3.03 \\
(17.16)\end{array}$ & $\{0.50\}$ & -.004 \\
\hline Belgium & $\begin{array}{c}3.40 \\
(1.04)\end{array}$ & {$[0.01]$} & .036 & $\begin{array}{c}25.82 \\
(12.64)\end{array}$ & {$[0.10]$} & .061 & $\begin{array}{c}43.04 \\
(53.00)\end{array}$ & {$[0.37]$} & .020 \\
\hline Canada & $\begin{array}{c}0.65 \\
(0.49)\end{array}$ & {$[0.10]$} & .002 & $\begin{array}{c}3.96 \\
(4.68)\end{array}$ & {$[0.29]$} & .007 & $\begin{array}{c}-3.22 \\
(12.13)\end{array}$ & {$[0.59\}$} & .006 \\
\hline France & $\begin{array}{l}2.10 \\
(0.53)\end{array}$ & {$[0.00]$} & .042 & $\begin{array}{c}3.07 \\
(5.92)\end{array}$ & {$[0.37]$} & -.001 & $\begin{array}{c}-9.26 \\
(10.53)\end{array}$ & {$[0.71]$} & .015 \\
\hline Germany & $\begin{array}{l}-0.05 \\
(0.17)\end{array}$ & {$[0.58]$} & -.003 & $\begin{array}{l}-1.65 \\
(1.82)\end{array}$ & {$[0.73]$} & .007 & $\begin{array}{l}-5.87 \\
(3.95)\end{array}$ & {$[0.81]$} & .031 \\
\hline Italy & $\begin{array}{c}0.43 \\
(0.39)\end{array}$ & {$[0.13]$} & .003 & $\begin{array}{c}-0.24 \\
(6.58)\end{array}$ & $(0.52)$ & -.003 & $\begin{array}{l}-20.16 \\
(26.95)\end{array}$ & {$[0.69]$} & .043 \\
\hline Japan & $\begin{array}{c}0.76 \\
(0.45)\end{array}$ & {$[0.05]$} & .011 & $\begin{array}{l}-0.11 \\
(5.46)\end{array}$ & $10.51]$ & -.004 & $\begin{array}{l}-17.19 \\
(11.63)\end{array}$ & {$[0.81]$} & .092 \\
\hline Netherlands & $\begin{array}{c}0.07 \\
(0.31)\end{array}$ & {$[0.40]$} & -.003 & $\begin{array}{l}-2.99 \\
(3.22)\end{array}$ & $\{0.73\}$ & .019 & $\begin{array}{r}-13.63 \\
(6.03)\end{array}$ & {$[0.89]$} & .125 \\
\hline Sweden & $\begin{array}{c}0.44 \\
(0.31)\end{array}$ & {$[0.09]$} & .002 & $\begin{array}{l}-0.84 \\
(2.65)\end{array}$ & $\$ 0.59]$ & .001 & $\begin{array}{r}-10.01 \\
(3.78)\end{array}$ & $\{0.92\}$ & .226 \\
\hline Switzerland & $\begin{array}{c}0.22 \\
(0.24)\end{array}$ & {$[0.18]$} & -.001 & $\begin{array}{l}-1.28 \\
(3.79)\end{array}$ & {$[0.59]$} & .002 & $\begin{array}{r}-12.52 \\
(3.66)\end{array}$ & {$[0.96]$} & .336 \\
\hline $\begin{array}{l}\text { United } \\
\text { Kingdom }\end{array}$ & $\begin{array}{l}-0.14 \\
(0.88)\end{array}$ & {$[0.54]$} & -.003 & $\begin{array}{l}-2.33 \\
(6.32)\end{array}$ & {$[0.60]$} & -.002 & $\begin{array}{l}-53.98 \\
(22.00)\end{array}$ & {$[0.91]$} & .203 \\
\hline $\begin{array}{l}\text { United } \\
\text { States }\end{array}$ & $\begin{array}{c}1.72 \\
(0.77)\end{array}$ & {$[0.02]$} & .012 & $\begin{array}{l}15.41 \\
(6.00)\end{array}$ & {$[0.05]$} & .081 & $\begin{array}{c}-6.49 \\
(16.52)\end{array}$ & $\{0.52\}$ & $.00 t_{4}$ \\
\hline Average & $\begin{array}{c}0.85 \\
(0.29)\end{array}$ & {$[0.01]$} & & $\begin{array}{c}2.65 \\
(2.44)\end{array}$ & {$[0.24]$} & & $\begin{array}{r}-10.21 \\
(7.75)\end{array}$ & $10.78 \mathrm{j}$ & \\
\hline $\begin{array}{l}\text { US } \\
1926-1988\end{array}$ & $\begin{array}{c}0.13 \\
(0.13)\end{array}$ & {$[0.16]$} & .004 & $\begin{array}{c}1.62 \\
(0.45)\end{array}$ & $\{0.01\}$ & .055 & $\begin{array}{c}5.57 \\
(1.63)\end{array}$ & {$[0.04]$} & .124 \\
\hline
\end{tabular}

Each entry reports estimates of the coefficient $\beta_{1, k}$ from the regression:

$$
\mathrm{R}_{\mathrm{t}, \mathrm{k}}=\alpha_{k}+\beta_{k} *\left(\mathrm{z}_{\mathrm{t}}-\mathrm{p}_{\mathrm{t}}\right)+v_{t, k}
$$

where $z_{t}$ is the logarithm of the reciprocal of the short term interest rate. Data are from 1960-1988; see Appendix Table Al for specifics. The coefficients are biasadjusted. Numbers in parentheses are standard errors, calculated using the Newey-Wes procedure. The standard error of the average accounts for cross correlation of the coefficients. Numbers in brackets are p-values for the null hypothesis that the coefficient is zero, based on the Monte Carlo distribution of the adjusted t-statisti 
Table 9: Forecasting Excess Foreign Holding Returns Using Real Exchange Rates

\begin{tabular}{|c|c|c|c|c|c|c|c|c|c|}
\hline Country & $\beta_{1}$ & $\begin{array}{l}1 \text { Month } \\
\text { p-value }\end{array}$ & $\bar{R}^{2}$ & $\beta_{12}$ & $\begin{array}{l}12 \text { Month } \\
\text { p-value }\end{array}$ & $\overline{\mathrm{R}}^{2}$ & $\beta_{48}$ & $\begin{array}{r}48 \text { Month } \\
\text { p-value }\end{array}$ & $\overline{\mathrm{R}}^{2}$ \\
\hline \multicolumn{10}{|c|}{ United States } \\
\hline France & $\begin{array}{l}-0.98 \\
(1.03)\end{array}$ & $10.80]$ & .003 & $\begin{array}{l}-1.88 \\
(14.21)\end{array}$ & {$[0.59]$} & .129 & $\begin{array}{r}34.43 \\
(34.94)\end{array}$ & $10.49\}$ & .455 \\
\hline Germany & $\begin{array}{l}-1.44 \\
(1.03)\end{array}$ & $(0.88)$ & -.002 & $\begin{array}{c}-9.44 \\
(14.10)\end{array}$ & {$[0.701$} & .071 & $\begin{array}{c}-9.32 \\
(33.66)\end{array}$ & $\{0.67\}$ & .252 \\
\hline Japan & $\begin{array}{c}0.58 \\
(1.79)\end{array}$ & {$[0.40]$} & .007 & $\begin{array}{c}29.72 \\
(21.58)\end{array}$ & {$[0.28]$} & .212 & $\begin{array}{l}150.63 \\
(13.82)\end{array}$ & {$[0.01\}$} & .715 \\
\hline $\begin{array}{l}\text { United } \\
\text { Kingdom }\end{array}$ & $\begin{array}{r}0.61 \\
(1.28)\end{array}$ & {$[0.35]$} & .019 & $\begin{array}{r}18.74 \\
(13.17)\end{array}$ & {$[0.27\}$} & .272 & $\begin{array}{l}122.56 \\
(19.17)\end{array}$ & {$[0.06]$} & .813 \\
\hline
\end{tabular}

Japan

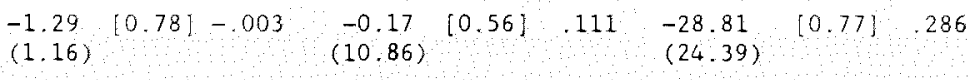

Germany

$-1.64 \quad\{0.83]-.004$

$\begin{array}{llllll}-8.97 & {[0.74]} & 051 & -67.42\end{array}$

(10.31) $(20.32)$

$[0.91] \quad .024$

(1.15)

United

$0.22[0.53] \quad .009$

$21.28 \cdot[0.26]$

.222

96.30

(18.90)

$[0.10] \quad .592$

Kingdom

(1.42) $(14.12)$

(1)

\section{United Kingdom}

\begin{tabular}{|c|c|c|c|c|c|c|c|}
\hline France & $\begin{array}{l}-0.87) \\
(1.66)\end{array}$ & {$[0.68]-.002$} & $\begin{array}{r}-9.06 \\
(11.69)\end{array}$ & {$[0.72]$} & .024 & $\begin{array}{r}24.30 \\
(24.75)\end{array}$ & {$[0.49]$} \\
\hline Germany & $\begin{array}{l}-1.46 \\
(1.41)\end{array}$ & $\{0.82\}-.004$ & $\begin{array}{l}-9.81 \\
(10.11)\end{array}$ & {$[0.75]$} & .032 & $\begin{array}{l}-24.63 \\
(28.18)\end{array}$ & {$[0.74]$} \\
\hline
\end{tabular}

Germany

France

$\begin{array}{lll}4.05 & {[0.06] \quad .033}\end{array}$

$63.00 \quad[0.05] \quad .452$

$21.15 \div[0.49]$

.086

(2.28)

(17.43)

(21.42)

Average

-0.22
$(0.55)$$[0.65]$

$9.34 \quad[0.30]$

$31.92 \div[0.43]$

(7. 55$)$

(22.38)

Each entry reports estimates of the coefficient $\beta_{1, k}$ from the regression:

$$
R_{t, k}=\alpha_{k}+\beta_{k}^{*}\left(z_{t}-p_{t}\right)+v_{t, k}
$$

where $z_{t}$ is a constant and $p_{t}$ is the logarithm of the real exchange rate. Data are from 1974-1988. The coefficients are bias-adjusted. Numbers in parentheses are standard errors, calculated using the Newey-West procedure. The standard error of the average accounts for cross correlation of the coefficients, as in the text. Numbers in brackets are p-values for the null hypothesis that the coefficient is zero, based on the Monte Carlo distribution of the adjusted t-statistic. 
Table 10: Forecasting Precious Metal Returns Using Lagged Fundamentals

\begin{tabular}{|c|c|c|c|c|c|c|c|c|c|}
\hline Country & $\beta_{1}$ & $\begin{array}{l}1 \text { Month } \\
\text { p-value }\end{array}$ & $\overline{\mathrm{R}}^{2}$ & $\beta_{12}$ & $\begin{array}{l}12 \text { Month } \\
\text { p-value }\end{array}$ & $\overline{\mathrm{R}}^{2}$ & $\beta_{48}$ & $\begin{array}{l}48 \text { Month } \\
\text { p-value }\end{array}$ & $\bar{R}^{2}$ \\
\hline Gold & $\begin{array}{c}0.94 \\
(1.79)\end{array}$ & {$[0.33]$} & .012 & $\begin{array}{l}27.05 \\
(13.06)\end{array}$ & 10.171 & .235 & $\begin{array}{l}133.19 \\
(20.98)\end{array}$ & $\{0.06\}$ & .871 \\
\hline Silver & $\begin{array}{c}2.92 \\
(2.51)\end{array}$ & {$[0.16]$} & .017 & $\begin{array}{c}27.49 \\
(14.68)\end{array}$ & $10.20]$ & .188 & $\begin{array}{l}109.00 \\
(32.75)\end{array}$ & {$[0.22]$} & .451 \\
\hline $\begin{array}{l}\text { Metal } \\
\text { Index }\end{array}$ & $\begin{array}{l}-0.18 \\
(0.93)\end{array}$ & $\{0.55\}$ & .000 & $\begin{array}{l}14.05 \\
(10.51)\end{array}$ & $0.19]$ & .094 & $\begin{array}{c}29.69 \\
(35.31)\end{array}$ & $\{0.37\}$ & .150 \\
\hline
\end{tabular}

Each entry reports estimates of the coefficient $\beta_{1, k}$ from the regression:

$$
\mathrm{R}_{\mathrm{t}, \mathrm{k}}=\alpha_{\mathrm{k}}+\beta_{\mathrm{k}} *\left(\mathrm{z}_{\mathrm{t}}-\mathrm{p}_{\mathrm{t}}\right)+v_{\mathrm{t}, \mathrm{k}}
$$

where $p_{t}$ is the logarithm of the real price of the metal or the value of the index. The fundamental $z_{t}$ is assumed to be a constant. Data are from $1974-1988$ for gold and silver, and from 1959-1988 the the metal index. The coefficients are biasmadjuted. Numbers in parentheses are standard errors, calculated using the Newey-west procedure. Numbers in brackets are p-values for the nul hypothesis that the adjusted coefficient is zero, based on the Monte Carlo distribution of the adjusted t-statistic. 
Table 11: Dividend Price Ratios and the Effect of Volatility

\begin{tabular}{|c|c|c|c|c|c|c|}
\hline Country & $\begin{array}{l}1 \text { Mont } \\
\beta_{1}\end{array}$ & $\begin{array}{c}\text { Return } \\
\gamma_{1}\end{array}$ & $\begin{array}{c}12 \text { Mon } \\
\beta_{12}\end{array}$ & $\begin{array}{c}\text { Return } \\
\gamma_{12}\end{array}$ & $\begin{array}{l}48 \text { Mon } \\
\beta_{48}\end{array}$ & $\begin{array}{c}\text { Return } \\
\gamma_{48}\end{array}$ \\
\hline Australia & $\begin{array}{l}3.84 \\
(2.07)\end{array}$ & $\begin{array}{c}0.25 \\
(0.70)\end{array}$ & $\begin{array}{l}45.83 \\
(8.93)\end{array}$ & $\begin{array}{l}-3.85 \\
(4.45)\end{array}$ & $\begin{array}{l}108.26 \\
(14.36)\end{array}$ & $\begin{array}{r}8.36 \\
(7.07)\end{array}$ \\
\hline Austria & $\begin{array}{l}-0.46 \\
(1.37)\end{array}$ & $\begin{array}{c}0.41 \\
(0.27)\end{array}$ & $\begin{array}{l}-11.32 \\
(18.79)\end{array}$ & $\begin{array}{c}0.09 \\
(3.07)\end{array}$ & $\begin{array}{c}57.24 \\
(55.32)\end{array}$ & $\begin{array}{r}17.90 \\
(13.96)\end{array}$ \\
\hline Belgium & $\begin{array}{l}-0.48 \\
(1.01)\end{array}$ & $\begin{array}{c}0.73 \\
(0.38)\end{array}$ & $\begin{array}{r}-0.76 \\
(9.77)\end{array}$ & $\begin{array}{l}7.62 \\
(3.04)\end{array}$ & $\begin{array}{c}36.65 \\
(24.08)\end{array}$ & $\begin{array}{c}20.29 \\
(11.65)\end{array}$ \\
\hline Canada & $\begin{array}{c}1.00 \\
(1.94)\end{array}$ & $\begin{array}{r}0.19 \\
(0.58)\end{array}$ & $\begin{array}{r}32.58 \\
(12.60)\end{array}$ & $\begin{array}{l}-4.23 \\
(4.03)\end{array}$ & $\begin{array}{c}55.56 \\
(19.19)\end{array}$ & $\begin{array}{c}1.26 \\
(5.11)\end{array}$ \\
\hline France & $\begin{array}{c}0.08 \\
(0.99)\end{array}$ & $\begin{array}{l}1.33 \\
(0.57)\end{array}$ & $\begin{array}{r}9.04 \\
(8.10)\end{array}$ & $\begin{array}{c}1.02 \\
(3.89)\end{array}$ & $\begin{array}{c}55.59 \\
(27.36)\end{array}$ & $\begin{array}{r}-2.06 \\
(11.98)\end{array}$ \\
\hline Germany & $\begin{array}{c}1.29 \\
(1.22)\end{array}$ & $\begin{array}{r}0.39 \\
(0.38)\end{array}$ & $\begin{array}{r}29.40 \\
(11.68)\end{array}$ & $\begin{array}{c}8.08 \\
(3.28)\end{array}$ & $\begin{array}{c}64.57 \\
(20.43)\end{array}$ & $\begin{array}{l}14.67 \\
(9.57)\end{array}$ \\
\hline Italy & $\begin{array}{c}0.51 \\
(1.49)\end{array}$ & $\begin{array}{l}-0.38 \\
(0.66)\end{array}$ & $\begin{array}{r}9.31 \\
(13.49)\end{array}$ & $\begin{array}{l}-7.45 \\
(6.60)\end{array}$ & $\begin{array}{c}37.59 \\
(32.19)\end{array}$ & $\begin{array}{l}39.96 \\
(8.72)\end{array}$ \\
\hline Japar & $\begin{array}{c}-1.20 \\
(0.41)\end{array}$ & $\begin{array}{l}-0.07 \\
(0.34)\end{array}$ & $\begin{array}{r}-13.27 \\
(4.60)\end{array}$ & $\begin{array}{l}-1.42 \\
(3.29)\end{array}$ & $\begin{array}{l}-52.55 \\
(24.63)\end{array}$ & $\begin{array}{r}-11.44 \\
(8.82)\end{array}$ \\
\hline Netherlands & $\begin{array}{c}0.49 \\
(1.31)\end{array}$ & $\begin{array}{c}0.71 \\
(0.56)\end{array}$ & $\begin{array}{r}12.52 \\
(10.61)\end{array}$ & $\begin{array}{l}10.90 \\
(3.12)\end{array}$ & $\begin{array}{c}73.14 \\
(24.33)\end{array}$ & $\begin{array}{c}20.54 \\
(10.41)\end{array}$ \\
\hline Sweden & $\begin{array}{c}0.35 \\
(1.04)\end{array}$ & $\begin{array}{c}0.73 \\
(0.44)\end{array}$ & $\begin{array}{r}16.44 \\
(11.60)\end{array}$ & $\begin{array}{c}5.73 \\
(4.30)\end{array}$ & $\begin{array}{c}60.97 \\
(38.08)\end{array}$ & $\begin{array}{l}22.42 \\
(7.96)\end{array}$ \\
\hline Switzerland & $\begin{array}{r}2.98 \\
(1.75)\end{array}$ & $\begin{array}{l}0.28 \\
(0.41)\end{array}$ & $\begin{array}{l}28.72 \\
(10.70)\end{array}$ & $\begin{array}{l}3.30 \\
(3.59)\end{array}$ & $\begin{array}{l}70.65 \\
(26.14)\end{array}$ & $\begin{array}{l}16.26 \\
(8.51)\end{array}$ \\
\hline $\begin{array}{l}\text { United } \\
\text { Kingdon }\end{array}$ & $\begin{array}{l}2.59 \\
(1.71)\end{array}$ & $\begin{array}{c}0.46 \\
(0.51)\end{array}$ & $\begin{array}{r}42.28 \\
(11.93)\end{array}$ & $\begin{array}{c}2.37 \\
(2.85)\end{array}$ & $\begin{array}{l}91.67 \\
(21.14)\end{array}$ & $\begin{array}{l}18.48 \\
(5.40)\end{array}$ \\
\hline $\begin{array}{l}\text { United } \\
\text { States }\end{array}$ & $\begin{array}{l}-0.10 \\
(1.05)\end{array}$ & $\begin{array}{r}0.56 \\
(0.37)\end{array}$ & $\begin{array}{r}6.39 \\
(9.05)\end{array}$ & $\begin{array}{l}3.54 \\
(2.62)\end{array}$ & $\begin{array}{l}11.18 \\
(23.31)\end{array}$ & $\begin{array}{l}0.67 \\
(4.18)\end{array}$ \\
\hline Average & $\begin{array}{c}0.84 \\
(0.41)\end{array}$ & $\begin{array}{c}0.43 \\
(0.24)\end{array}$ & $\begin{array}{l}15.94 \\
(5.24)\end{array}$ & $\begin{array}{c}1.98 \\
(1.49)\end{array}$ & $\begin{array}{c}51.58 \\
(11.00)\end{array}$ & $\begin{array}{l}12.87 \\
(3.69)\end{array}$ \\
\hline $\begin{array}{l}\text { United States } \\
(1926-1988)\end{array}$ & $\begin{array}{c}1.19 \\
(0.83)\end{array}$ & $\begin{array}{l}-0.27 \\
(0.25)\end{array}$ & $\begin{array}{l}22.86 \\
(6.94)\end{array}$ & $\begin{array}{l}-4.48 \\
(3.28)\end{array}$ & $\begin{array}{r}76.18 \\
(14.92)\end{array}$ & $\begin{array}{l}-2.37 \\
(6.98)\end{array}$ \\
\hline
\end{tabular}

Each entry reports estimates of the coefficients $\beta_{k}$ and $\gamma_{k}$ from the regression:

$$
R_{t, k}=\alpha_{k}+\beta_{k} *\left(z_{t}-p_{t}\right)+\gamma_{k} * \ln \left(V_{o l}\right)+u_{t, k}
$$

where $z_{t}$ is the logarithm of the real dividend for the market and volatility is the sum of squared monthly returns for the past twelve months. The sample period is 1960-1988; see Appendix Table Al for specifics. The coefficients are bias-adjusted. Standard. errors, in parentheses, are calculated using the Newey-West procedure with 11 or 47 lags for 12 and 48 month returns, respectively. 
Table Al: Sample Period

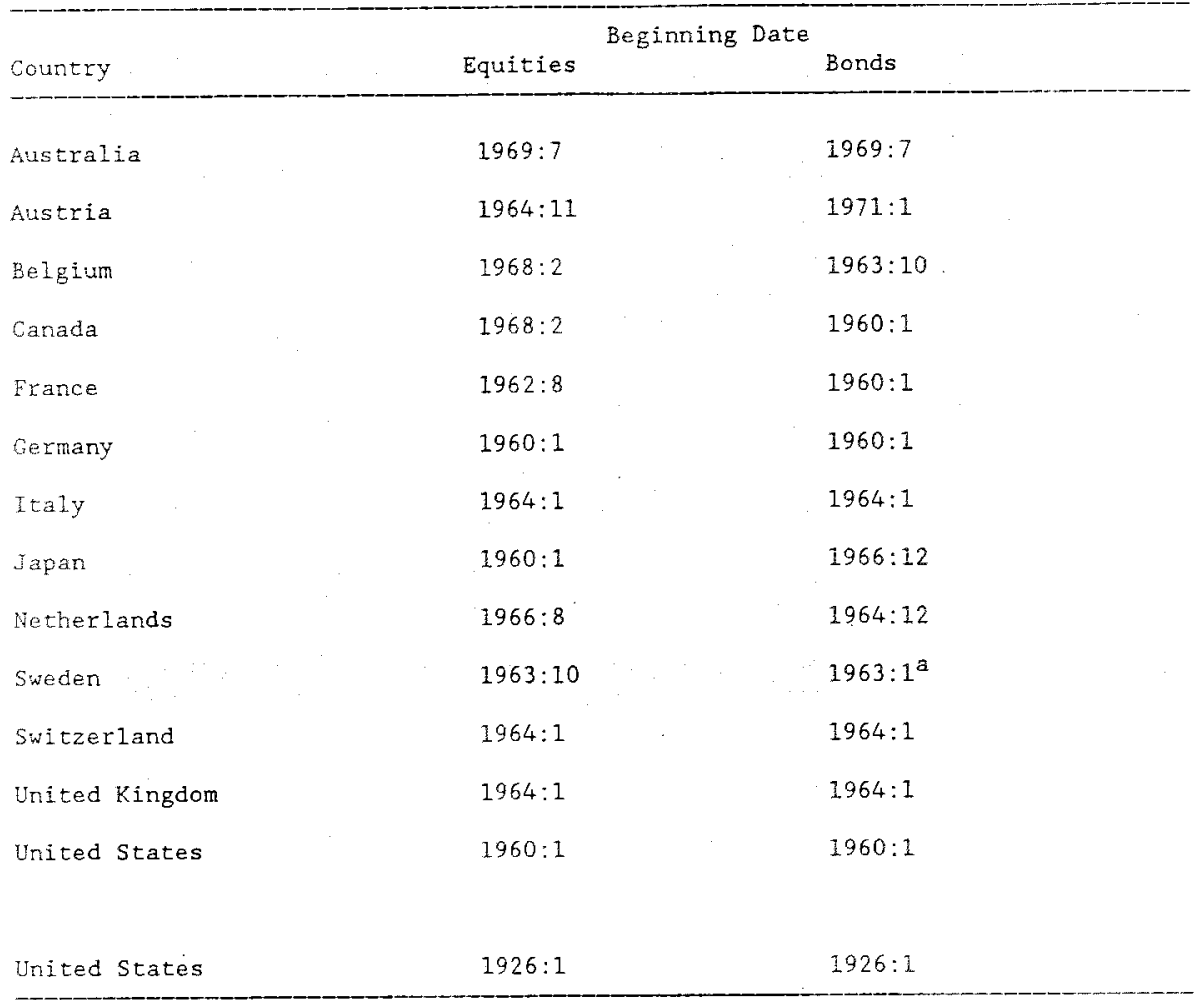

The table shows the starting period for the equity and bond market regressions. The ia. for Swedish bond returns indicates that the sample period ends in $1988: 1$. 
Figure 1

Power of Regression Test

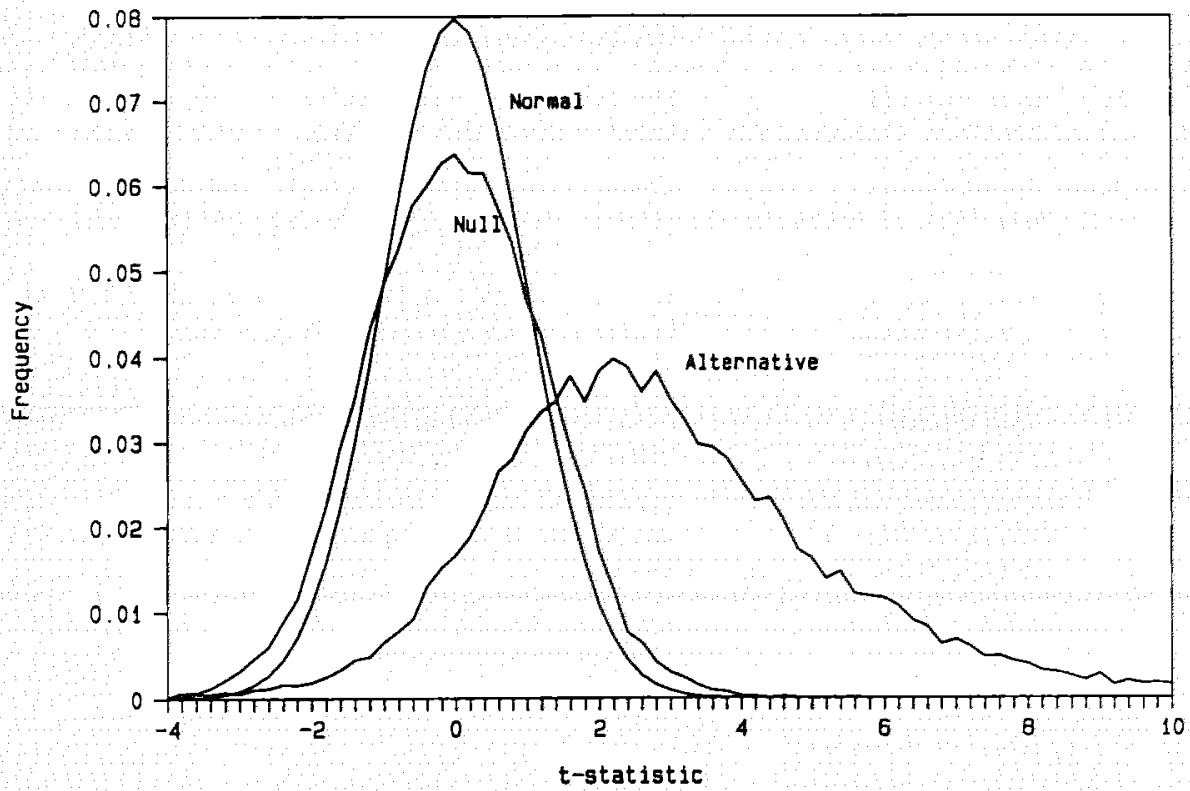

Note: Figure shows enpirical distribution of the t-statistic for 48-month regression. The distributions are based on 25, 000 replications. The paraneters are: rho=.99, delta=.75. and lambda-1.0. Each point is an interval of .20 In the distribution. 